\title{
CALSOYASUCHUS VALLICEPS, A NEW CROCODYLIFORM FROM THE EARLY JURASSIC KAYENTA FORMATION OF ARIZONA
}

\author{
RONALD S. TYKOSKI ${ }^{1,2}$, TIMOTHY B. ROWE ${ }^{1,2,3}$, RICHARD A. KETCHAM ${ }^{1,3}$, and MATTHEW W. COLBERT ${ }^{1,2,3}$ \\ ${ }^{1}$ Jackson School of Geosciences, tykoski@mail.utexas.edu; \\ ${ }^{2}$ Texas Memorial Museum Vertebrate Paleontology Laboratory; \\ ${ }^{3}$ High Resolution X-ray CT Facility, The University of Texas at Austin, Austin, Texas 78712
}

\begin{abstract}
We describe a new fossil crocodyliform archosaur from the Early Jurassic Kayenta Formation of the Navajo Nation that is surprisingly derived for so ancient a specimen. High-resolution X-ray CT analysis reveals that its long snout houses an extensive system of pneumatic paranasal cavities. These are among the most distinctive features of modern crocodylians, yet the evolutionary history of this unique system has been obscured by the inaccessibility of internal structures in most fossil crania. Preliminary phylogenetic analysis indicates that the new species is the oldest known member of a monophyletic Goniopholididae, and within this lineage to be the sister taxon of Eutretauranosuchus, from the Late Jurassic Morrison formation of Colorado. Goniopholididae became extinct at the end of the Cretaceous, but it is more closely related to living crocodylians than are several lineages known only from Cretaceous and younger fossils. The new taxon nearly doubles the known length of goniopholid history and implies a deep, as yet undiscovered, Mesozoic history for several crocodyliform lineages that were once thought to have relatively complete fossil records.
\end{abstract}

\section{INTRODUCTION}

In the summer of 1997, a collaboration involving the Texas Memorial Museum of The University of Texas at Austin, the Museum of Comparative Zoology of Harvard University, and the Seba Dalkai Navajo Nation School sent crews to prospect exposures of the Early Jurassic Kayenta Formation. These exposures lie on lands of the Navajo Nation in northeastern Arizona. The Navajo Nation requires permits to conduct paleontological work on its lands, and our work was carried out under permits kindly granted by the Navajo Nation Minerals Division. The Kayenta Formation is generally considered to be Early Jurassic in age (Sinemurian-Pliensbachian; Clark and Fastovsky, 1986; Sues et al., 1994). Its beds previously yielded a rich diversity of fossil tetrapod taxa (Clark, 1986; Clark and Fastovsky, 1986; Sues et al., 1994), including a caecilian (Jenkins and Walsh, 1993), an anuran (Shubin and Jenkins, 1995; Jenkins and Shubin, 1998), a turtle (Gaffney et al., 1987), several crocodylomorphs (Crompton and Smith, 1980; Clark, 1986, 1994), a pterosaur (Padian, 1984), a sauropodomorph (Attridge et al., 1985), theropods (Welles, 1954, 1970, 1984; Rowe, 1989; Tykoski, 1998), ornithischians (Colbert, 1981), tritylodontids (Kermack, 1982; Sues, 1985, 1986a, 1986b), and morganucodontids (Jenkins et al., 1983; Crompton and Luo, 1993).

A number of new specimens were recovered in the course of our collaboration, including a partial skull of a distinctive new crocodylomorph that is unlike any previously reported from Early Jurassic sediments. Representing a new species, this taxon adds to a diverse list of Kayenta crocodylomorphs that includes Eopneumatosuchus colberti (Crompton and Smith, 1980), three undescribed protosuchian-grade taxa, and an undescribed sphenosuchid-grade form (Clark, 1986; Clark and Fastovsky, 1986; Sues et al., 1994).

Our study of the new specimen was greatly assisted by scanning it at The University of Texas High Resolution X-ray Computed Tomography (CT) Facility (Rowe et al., 1997; Ketcham and Carlson, 2001). The CT imagery revealed the internal anatomy of extensive paranasal pneumatic cavities within the rostrum, and it helped distinguish between cracks and sutures. It was also used to generate several of the illustrations (Figs. 1-
7) for this report. Two of these figures (Figs. 1A, C, 2A, C) include volumetric reconstructions of the skull that were computer-generated from the original CT slices. Although they look superficially like conventional photographs, volumetric reconstructions show far more structural detail than photos (Figs. 79), particularly the presence of numerous minute fractures that are invisible to both the camera and the naked eye. The photos (Figs. 7-9) convey a more readily interpretable picture of the relatively good quality of preservation of the specimen.

All of our original high-resolution X-ray CT data accompany this article on a supplemental CD-ROM (Table 1). Also included on the CD-ROM are serial section animations and animated 3D volumetric reconstructions of the skull. Reduced-resolution versions of the slice and volumetric animations are available on the World Wide Web (http://www.digimorph.org/specimens/calsoyasuchusvalliceps/). Also included on the CD-ROM is a surface model of the specimen in stereolithography (STL) format, which can be interactively viewed with an appropriate player. Stereolithography files have now been published for the endocast of the Triassic cynodont Thrinaxodon (Rowe et al., 1995) and the skull of Alligator mississippiensis (Rowe et al., 1999a, b). They are of special interest to the readership of this journal because stereolithography files can be rendered using a growing array of rapid prototyping technologies that transform digital 3D objects into physical 3D objects (e.g., Juricic and Barr, 1996). These models can be scaled up or down and rendered at any desired size (within the physical limits of the particular rapid prototyping device used). Thus, with the appropriate equipment, a detailed physical replica resembling a conventional cast of the specimen can be generated from the file on the accompanying CD-ROM.

A series of analyses of crocodylomorph phylogeny published over the last two decades provided a strong framework in which to diagnose and evaluate the affinities of the new taxon (Clark, 1986, 1994; Benton and Clark, 1988; Clark and Norell, 1992; Brochu, 1997a, b, 1999; Wu et al., 1997; Buckley and Brochu, 1999; Buckley et al., 2000). We relied heavily on these studies to guide our estimation of the phylogenetic position of the new taxon. Until now, wide stratigraphic and morphological gaps separated the Late Jurassic and younger mesoeucrocodyliforms 
TABLE 1. Contents of supplemental CD-ROM imagery archive of the Calsoyasuchus holotype.

- CT_Data folder-CT slice files, 436 slice images in coronal slice plane, 8 and 16-bit TIF format

- STL folder-contains one 3D surface model of Calsoyasuchus holotype in stereolithography (STL) format

- Movies folder - contains two folders with animations requiring Quicktime software 3.0 or higher for viewing:

- 3D folder - contains six animated volumetric renderings of the holotype:

- Yaw: two movies in which skull rotates about vertical axis $(1=$ large format, $\mathrm{s}=$ small format $)$

- Roll: two movies in which skull rotates about long horizontal axis $(1=$ large format, $\mathrm{s}=$ small format $)$

- Pitch: two movies in which skull rotates about short horizontal axis $(1=$ large format, $\mathrm{s}=\mathrm{small}$ format $)$

O Slices folder-contains five slice-by-slice animations through complete CT data stacks; slice thickness is one millimeter; interslice spacing is $0.9 \mathrm{~mm}$ (i.e., 10 percent overlap of slices):

- Coronal (COR) - one movie through 436 slices taken in coronal plane, viewed from anterior to posterior

- Horizontal (HOR): two movies of 107 horizontal slices, viewed from dorsal to ventral, in large and small formats

- Sagittal (SAG): two movies of 138 vertical slices, viewed from left to right, in large and small formats

- Readme Describes in detail the contents and operation of files on the CD-ROM in Microsoft Word and Text formats.

- UTCT inspeCTor - java applet allowing interactive viewing of the scan data on the orthogonal axes.

from Triassic and Early Jurassic protosuchian-grade and sphenosuchian-grade crocodylomorphs (Langston, 1973). The new species is the oldest member of Goniopholididae, a clade with weak but unequivocal support in our analysis. The new species possesses a combination of primitive and derived features that helps to fill wide morphological and temporal gaps in early mesoeucrocodylian history. Its age and phylogenetic position suggest that the mesoeucrocodylian lineage, which was thought to possess one of the best records among fossil terrestrial vertebrates (Markwick, 1998), is far less complete than generally believed.

\section{MATERIALS AND METHODS}

\section{Type Specimen}

The holotype consists of a partial skull (Figs. 1A-D, 2A-D) found lying palate-side up, wedged between two pieces of petrified wood at the base of a trough scour within a thick, crossbedded channel sandstone bed. The skull was preserved in light-green, medium to coarse-grained sandstone, with hematitic crust over much of its surface. The posterior end of the skull was reduced by erosion to several dozen weathered pieces of surface float, which included portions of the braincase, suspensorium, and palate. These fragments are too weathered to reassemble with confidence, and are not described here. No postcranial elements were preserved.

Anatomical Abbreviations-Anatomical nomenclature in our description is based on Witmer (1995, 1997), Brochu (1999), and Rowe et al. (1999a, b): acc, accessory cavity; am, anterior palatal process of maxilla; aof, antorbital fenestra; ccr, caviconchal recess; dv, dorsal valley on nasals and frontal; $\mathbf{d p m}$, dorsal process of premaxilla; en, external naris; $\mathbf{f}$, frontal; iaf, internal antorbital fenestra; ins, internarial septum; j, jugal; l, lacrimal; laf, lacrimal antorbital fossa; ls, laterosphenoid; m, maxilla; ma (1-29), maxillary alveolus; maf, maxillary antorbital fossa; md (1-29), maxillary tooth; mdep, maxillary depresssion; mmr, median maxillary ridge; n, nasal; ncp, nasal cavity proper; nlc, nasolacrimal canal; npd, nasopharyngeal duct; nv, nasal vestibule; occ, occlusal pit/pore; olf, impression of olfactory tracts on frontal; orb, orbit; pal, palatine; $\mathbf{p}$, parietal; pd (1-5), premaxillary tooth; pm, premaxilla; pma, premaxillary alveolus; po, postorbital; ppm, palatal process of premaxilla; pch, primary choana; prf, prefrontal; pt, pterygoid; pvr, postvestibular recess; q, quadrate; sac, secondary accessory cavity; sq, squamosal; stf, supratemporal fenestra; V, passage for maxillary branch of trigeminal nerve; vo, vomer. Left and right sides are differentiated by the prefixes "ll" and " $r$ ".

Citations in the text with the prefixes COR, HOR, and SAG refer respectively to relevant slice numbers in coronal, horizontal, and sagittal animations on the CD-ROM supplement.

Institutional Abbreviations-CMNH, Cleveland Museum of Natural History, Cleveland, Ohio; TMM, Texas Memorial Museum, The University of Texas at Austin; YPM, Yale Peabody Museum, Yale University, New Haven.

\section{CT Scanning}

The specimen was scanned at the High-Resolution X-ray Computed Tomography (CT) Facility at the University of Texas at Austin, which is described by Ketcham and Carlson (2001). $\mathrm{X}$-ray energies were set to $420 \mathrm{kV}$ and $4.7 \mathrm{~mA}$, with a focal spot size of $1.8 \mathrm{~mm}$. X-rays were pre-filtered to reduce beam-hardening artifacts using two brass plates with a total thickness of $3.175 \mathrm{~mm}$. X-ray intensities were measured using an RLS detector with 2,048 channels spaced at $0.05 \mathrm{~mm}$ intervals. Forty channels were unsuitable for imaging, and the remaining channels were averaged into groups of 4 to reduce image noise, resulting in 502 effective channels with a spacing of $0.2 \mathrm{~mm}$. Each slice was acquired using 1,800 views (angular orientations), each view having an acquisition time of $64 \mathrm{~ms}$, and detector gain was set to 8 to maximize count rate. The resulting acquisition time was approximately 2 minutes per slice. The sample was scanned in a $190 \%$ offset mode (Ketcham and Carlson, 2001) with a slice thickness of $1.0 \mathrm{~mm}$ and an inter-slice spacing of $0.9 \mathrm{~mm}$. The image field of reconstruction was $130 \mathrm{~mm}$, and reconstruction parameters were calibrated to maximize usage of the 12-bit range of grayscales available in the output images.

At the time of the scan the detector showed behavior in which it would first drift rapidly out of calibration once data acquisition commenced, then drift more slowly. As a result it was decided to obtain the entire data set in one pass without recalibration during the scan. In order to minimize drift, the detector as exposed to X-rays for two hours before the scan began, and a very long signal calibration $(3,600$ views, or 3.84 minutes) was obtained. This procedure eliminated major problems, but nevertheless a drift in grayscale values of up to 7$8 \%$ occurred over the course of the scan. In general, the drift resulted in darkening in the center and brightening of the margins of the images as scanning progressed. The majority of this effect was removed from the data set by comparing initial and final images and analyzing intervening images to discern the pattern and course of the drift. Routines to perform this analysis and apply the subsequent correction were written in IDL version 5.3.1. For easier handling, the 12-bit data stored in 16-bit TIFF-format data files were exported to 8-bit format by dividing all grayscale values by 16 . The data are archived as individual slices.

The coronal slice-by-slice animation on the CD presents the original CT data. Owing to the length of the skull, the horizontal and sagittal animations are presented in reduced as well as full-sized versions. The latter may be too large to display completely on some current computer monitors. The coronal movie 

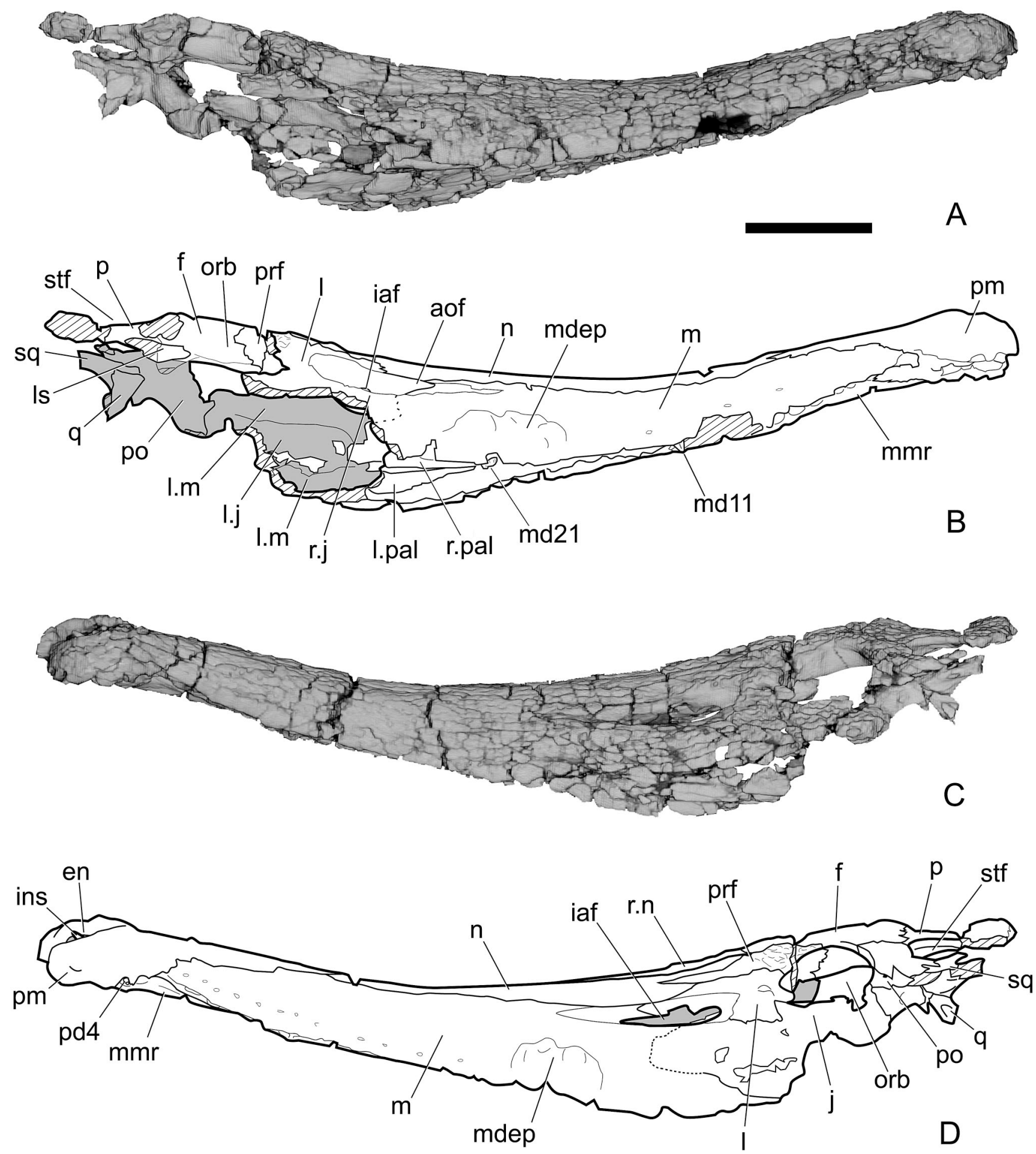

FIGURE 1. Right and left lateral views of Calsoyasuchus valliceps nov. (TMM 43631-1). A, computer generated volumetric visualization of skull in right lateral view; B, labeled line drawing of same; $\mathbf{C}$, volumetric visualization of skull in left lateral view; $\mathbf{D}$, labeled line drawing of same. Cross-hatched areas indicate broken bone. Shaded regions in B and D indicate deeply recessed or distant bone surface. The volumetric visualizations were derived from the CT dataset, and they show more fractures than are visible with the naked eye. Abbreviations in text. Scale bar equals $5 \mathrm{~cm}$.

(COR) begins at the tip of the right premaxilla; the slices are in anterior view. The horizontal movie (HOR) starts dorsally and passes ventrally; the slices are oriented in dorsal view. The sagittal movie (SAG) proceeds from right to left through the specimen; the slices are in left lateral view. The individual slice files used to generate the animations are at original size in the applet folder. These files can be viewed at or animated in their original dimensions using freely downloadable software such as NIH Image or ImageJ. Instructions for obtaining and using this software are included on the accompanying CD-ROM. 



FIGURE 2. Dorsal and ventral views of Calsoyasuchus valliceps nov. (TMM 43631-1). A, computer generated volumetric visualization of skull in dorsal view; $\mathbf{B}$, labeled line drawing of same; $\mathbf{C}$, volumetric visualization of skull in ventral view; $\mathbf{D}$, labeled line drawing of same. Cross-hatched areas indicate broken bone. Shaded regions in B and D indicate deeply recessed or distant bone surface. The volumetric visualizations were derived from the CT dataset, and they show more fractures than are visible with the naked eye. Abbreviations in text. Scale bar equals $5 \mathrm{~cm}$. 




FIGURE 3. Calsoyasuchus valliceps nov. (TMM 43631-1). Diagram showing the relative positions and orientations of the slice planes shown in Figures 4-6.

\section{Phylogenetic Analysis}

The pioneering work of Clark $(1986,1994)$ provided the first thorough cladistic analysis of ingroup relationships among crocodyliform archosaurs. Clark's work has served as the basis for several other cladistic analyses of crocodyliform relationships (Wu et al., 1997; Buckley and Brochu, 1999; Buckley et al., 2000), as well as for the one presented here. The aim of the present study is simply to estimate the position of the new taxon within the phylogenetic framework already established by these earlier studies. Consequently, our character list (Appendix 1) and matrix (Appendix 2) were modified minimally from those of Buckley et al. (2000). Some changes were made to reflect our reinterpretation of the anatomy of Eutretauranosuchus and Goniopholis. The new Kayenta taxon and the Asian taxon Sunosuchus (scored from the literature) were added to the character matrix, resulting in 27 taxa in the analysis (three outgroup taxa: 24 ingroup taxa). Two new characters were also added to the character list, bringing the total number to 119 (Appendix 1). Only about 43 percent of cranial characters (35 percent of total characters) could be scored for the new taxon owing to its incompleteness. We note that nearly $20 \%$ of these characters proved uninformative and consequently were ignored in our analyses. In addition, while scoring the character matrix for our new taxon, doubts arose over the independence among several characters (e.g., characters 11 and 12; characters 13 and 14). These problems may affect the precision of diagnoses for ingroup clades, but they are probably not serious problems in arriving at a tree topology. A more thorough analysis and treatment of these issues lies beyond the scope of the current work.

The comparative framework for our study of the new species follows Buckley et al. (2000) by including a sample of ingroup taxa consisting of Metriorhynchidae, Teleosauridae, Pelagosaurus, Hsisosuchus, Comahuesuchus, Baurusuchus, Sebecus, Libycosuchus, Notosuchus, Malawisuchus, Uruguaysuchus, Araripesuchus, Trematochampsa, Peirosauridae, Mahajangasu- chus, Alligatorium, Theriosuchus, Goniopholis, Sunosuchus, Eutretauranosuchus, Bernissartia, and Crocodylia. Comparisons were also drawn with an unnamed Early Cretaceous taxon widely discussed in the literature and known informally as the "Fruita taxon," a designation that we follow here. The new taxon was part of the ingroup as well.

We performed three analyses, all of which yielded identical tree topologies (see Discussion, below). In the first, all characters were treated as unordered, and uninformative characters were ignored. This yielded three trees of equal length (262 steps, $\mathrm{CI}=0.462, \mathrm{RI}=0.652)$. Following earlier authors, and at the urging of one reviewer, we also ordered several characters in two subsequent runs. In the first of these analyses, characters 15 and 49 were ordered, with no effect on tree topology. Three trees of equal length were found $(\mathrm{L}=262, \mathrm{CI}=0.462, \mathrm{RI}=$ $0.657)$. In the last analysis, characters $15,37,49,67$, and 77 were ordered and all other characters were unordered. This too had no effect on tree topology, but it lengthened the tree by two steps $(\mathrm{L}=264, \mathrm{CI}=0.458, \mathrm{RI}=0.655)$, and it altered the diagnoses of the various taxa found by the analysis. The taxon diagnoses presented below are based on analysis number one, in which all characters were treated as unordered. Our analysis was run on an Apple Macintosh G4 computer with PAUP 3.0s (Swofford, 1991), using a random, stepwise addition, heuristic search algorithm.

\section{SYSTEMATIC PALEONTOLOGY}

CROCODYLOMORPHA Walker, 1970 CROCODYLIFORMES Hay, 1930

MESOEUCROCODYLIA Whetstone and Whybrow, 1983 GONIOPHOLIDIDAE Cope, 1875

CALSOYASUCHUS VALLICEPS, sp. nov. (Figs. 1-9)

Etymology_Calsoyasuchus, "Calsoyas" to honor Dr. Kyril Calsoyas, former principal of Seba Dalkai Navajo Tribal 


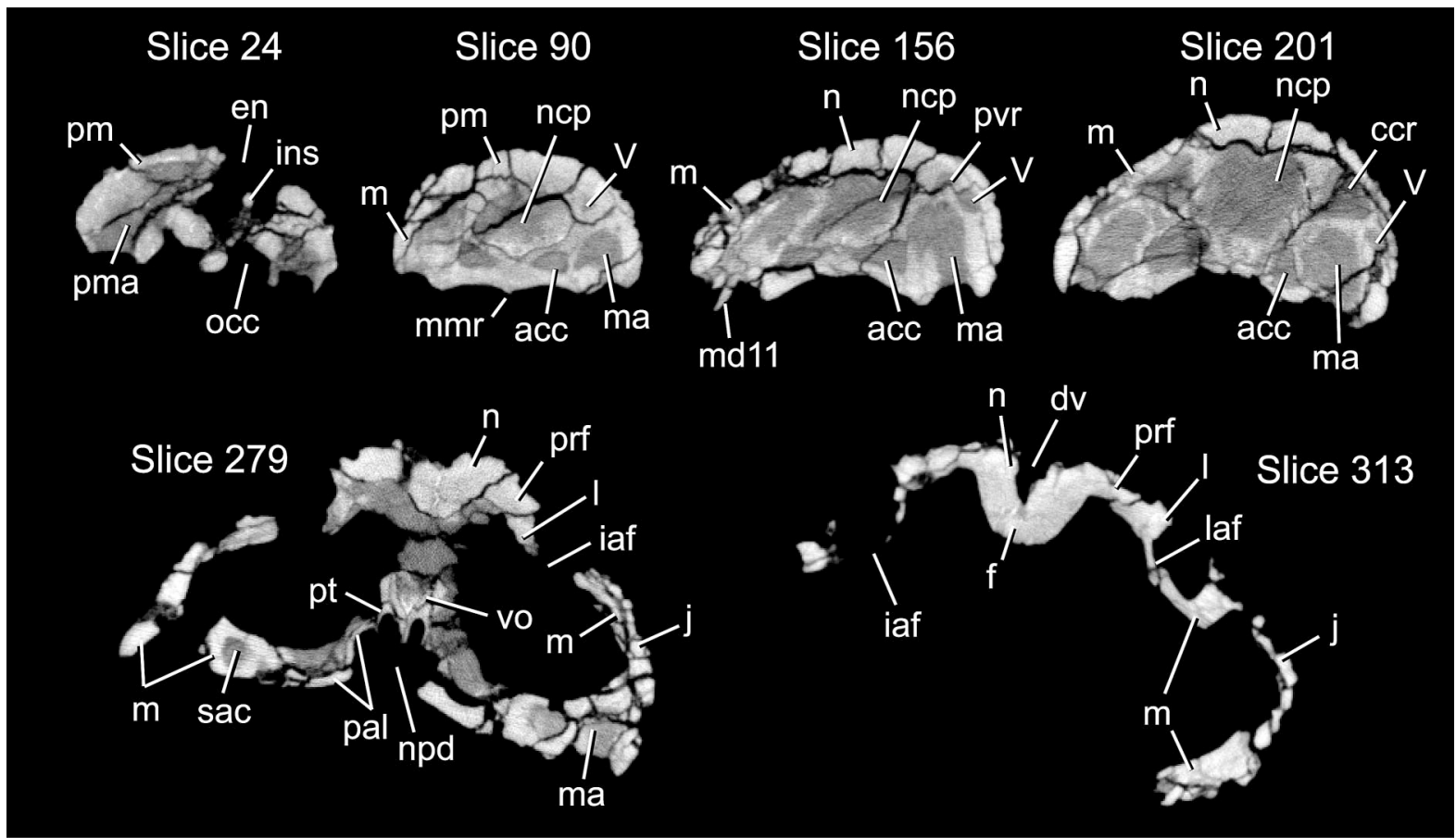

FIGURE 4. Calsoyasuchus valliceps nov. (TMM 43631-1). Selected CT slice images (slice numbers 24, 90, 156, 201, 279, and 313) through rostrum in coronal plane. See Figure 3 for position of slices through skull. Abbreviations in text.

School, our friend and gracious host in the Navajo Nation and a great champion of education, and souchos (Gr., derived from the Egyptian word for crocodile); valliceps, from combination of valles (L. valley), and cephale, (Gr. head), in reference to the deep median valley present on the dorsal surface of nasals and frontal bones.

Holotype-TMM 43631-1. Incomplete skull of a mediumsized crocodyliform, missing the occiput, braincase, most of the suspensorium, posterior portions of the palate, and jaws.

Occurrence-Locality TMM 43631 ("Calsoyasuchus hill”), field number TR 97/09, located in the northern part of the Gold Spring drainage basin, Adeii Eechii Cliffs, Navajo Nation, Coconino County, Arizona, in the middle third of the silty facies (Harshbarger et al., 1957; Clark and Fastovsky, 1986) of the Lower Jurassic (Early Jurassic: Sinemurian to Pliensbachian) Kayenta Formation.

Diagnosis - based on our phylogenetic analyses, a goniopholid with following apomorphies: lacrimal-nasal contact occurs only along anterior edge of lacrimal; frontal does not reach supratemporal fenestra; and teeth that are finely serrated. It is also equivocally diagnosed by a long, narrow internal antorbital fenestra whose length is slightly less than the orbit diameter. Other apomorphic features not scored in our analyses include: snout bowed downward and back upward so the tip of the rostrum is as high or more dorsally placed than skull table (when skull table is held horizontal); an internarial process rises from narial floor to partially divide external naris; the medial edges of the maxillary palatal processes curve ventrally, forming median ridge that descends below anterior alveolar border; medial maxillary accessory cavities very elongate; posterior end of maxilla divergent laterally, medially exposing the jugal anteroventral to the orbit; a deep pocket in medial surface of lacrimal anterior to the orbit; a deep and narrow median valley on posterior part of nasals and anterior third of frontal; lateral part of pterygoid anterior process with inverted " $U$ " cross-section posterior to primary choana.

\section{DESCRIPTION}

\section{General Appearance}

As preserved, the skull is approximately $380 \mathrm{~mm}$ long from the anterior tip of the rostrum to the most posterior preserved edge of the parietal. The braincase, occiput, the right and all but the anterodorsal end of the left quadrate, both quadratojugals, nearly all of the right squamosal, the posterior part of the left squamosal, posterior parts of the palatines, all but the anterior processes of the pterygoids, and most of the right and the posterior half of the left jugal were all eroded away prior to discovery (Figs. 1, 2). Identification of some sutures is difficult owing to numerous cracks and deeply sculptured ornamentation. Many of the cranial sutures are tightly closed. The original external shape of the skull is largely preserved and shows only minor distortion. CT imagery reveals that the geometry of the nasal cavity proper is largely preserved as well, and that the bones surrounding the nasal cavity are extensively pneumaticized (Figs. 3-6).

The skull is long and low in lateral view (Fig. 1A, D). When the skull table is oriented horizontally, the rostrum curves downwards from the orbits and then rises dorsally towards the rostral tip until it is slightly higher than the skull table. The snout is wider than tall throughout its length, although it is only slightly wider than tall near the premaxilla-maxilla contact. In coronal sections (Fig. 4) it has a rounded dorsal surface from the external naris to a plane just before the orbits, where a deep cleft marks the dorsal midline (Fig. 4, slice 313). The orbits are almost circular and are dorsolaterally oriented. An elongate external antorbital fenestra (sensu Witmer, 1995, 1997) excavates the posterior quarter of the snout. A narrow, elliptical internal antorbital fenestra (sensu Witmer, 1995, 1997) perforates the skull in the center of the external antorbital fenestra. Its long axis is almost equal in length to the orbit diameter. Both the external and internal antorbital fenestrae face more dorsally than laterally. Anteroventral to the antorbital fenestra is a de- 




FIGURE 5. Calsoyasuchus valliceps nov. (TMM 43631-1). Selected CT slice images (slice numbers 48, 57, and 69) through rostrum in sagittal plane. See Figure 3 for position of slices through skull. Abbreviations in text.

pression on the maxilla that lacks the rough sculpturing seen on the rest of the skull. The cranial roofing bones form a welldeveloped, flat skull table dorsal and posterior to the orbits.

In dorsal and ventral views (Fig. 2A, D) the snout is constricted at the premaxilla-maxilla junction. Behind this constriction the lateral margins of the snout are nearly straight as they diverge posteriorly toward the orbits. Adjacent to the fifth through seventh alveoli, the maxilla curves slightly outward to accommodate enlarged tooth roots. Between the 20th and 22nd maxillary alveoli, the skull broadens more noticeably, but not as sharply or to the degree seen in protosuchids and many longsnouted taxa (e.g., Gavialis; Iordansky, 1973; Langston, 1973; Crompton and Smith, 1980). The supratemporal fenestra measures only about half the diameter of the orbit. In this feature $C$. valliceps differs greatly from the other described Kayenta crocodylomorph, Eopnuematosuchus colberti (Crompton and Smith, 1980).

Ventrally, (Fig. 2C, D) the secondary palate forms an elongated floor beneath the nasal cavity. Posteriorly, the secondary palate ends at the primary choanae, but laterally the maxillae and palatines form broad shelves along either side of the ventrally open nasopharyngeal duct. Each primary choana is bounded anteriorly by the maxilla, laterally by the palatine, and medially by the anterior ramus of the pterygoid. The primary choanae open ventromedially into the nasopharyngeal duct. The CT imagery indicates that the most of the individual pneumatic cavities within the snout interconnect and become confluent with the nasal cavity proper in the vicinity of the primary choanae (COR 244-262).

\section{Bones of the Skull}

Premaxilla-The right premaxilla is broken through the fifth alveolus and displaced slightly dorsally and anteriorly. The left is unbroken and lies naturally articulated with the maxilla (Fig. 7A, B). The premaxillae are enlarged to form a swollen rostral tip that is wider than high, which accentuates a constriction in the snout at the premaxilla-maxilla juncture. At least four empty alveoli are visible in the right premaxilla, and five are present in the left (Figs. 2D, 7B). The first, second, and fifth alveoli are small. The third alveolus is the largest in the premaxilla whereas the fourth alveolus is intermediate in size between the second and third alveoli. CT imagery indicates that the alveoli invade the premaxilla deeply and reach almost to its dorsal surface (SAG 055-086; HOR 040-068). The poorly preserved base of the fourth tooth is present in the left premaxilla. The 


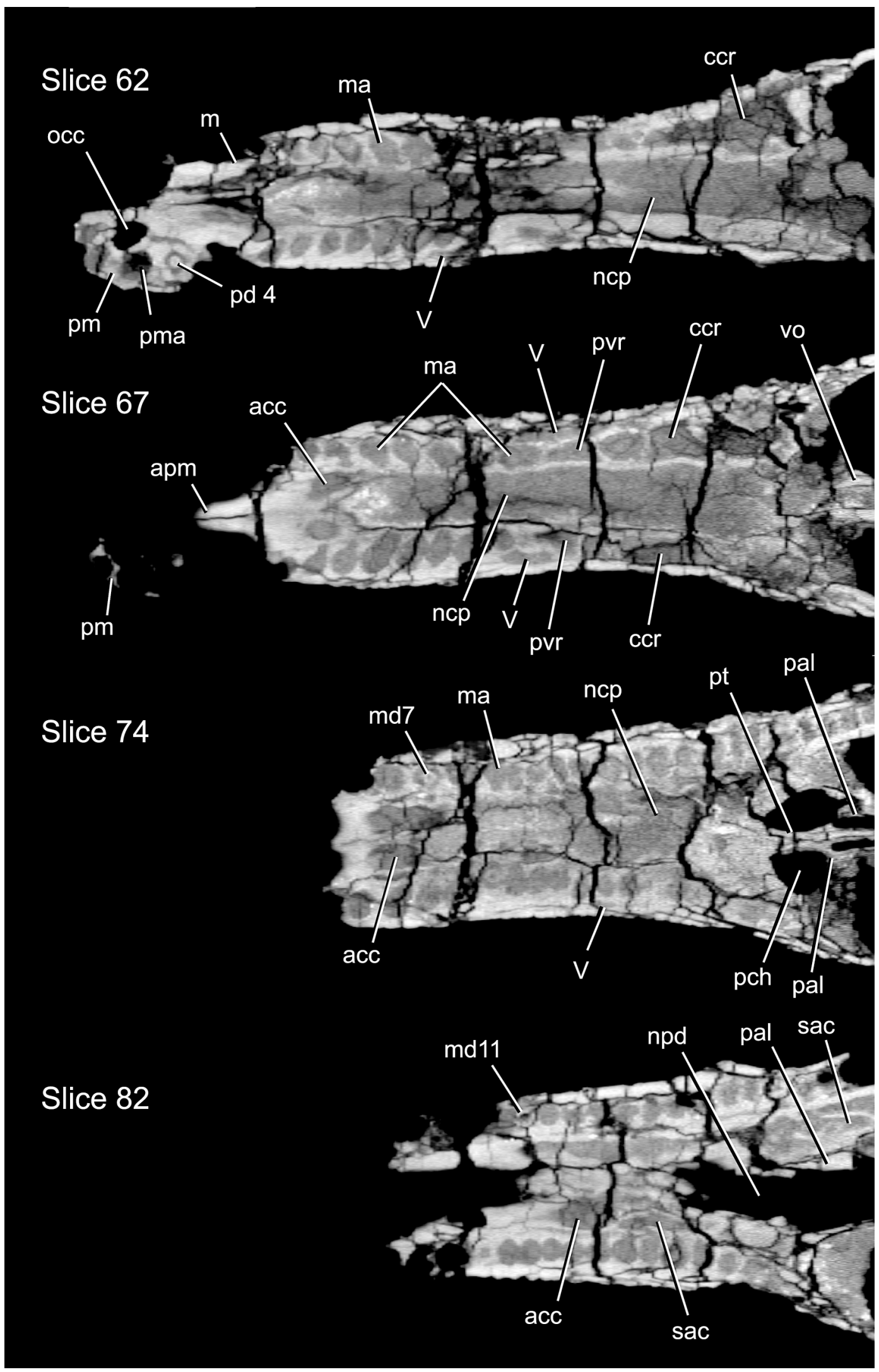

FIGURE 6. Calsoyasuchus valliceps nov. (TMM 43631-1). Selected CT slice images (slice numbers 62, 67, 74, and 82) through rostrum in horizontal plane. See Figure 3 for position of slices through skull. Abbreviations in text. 


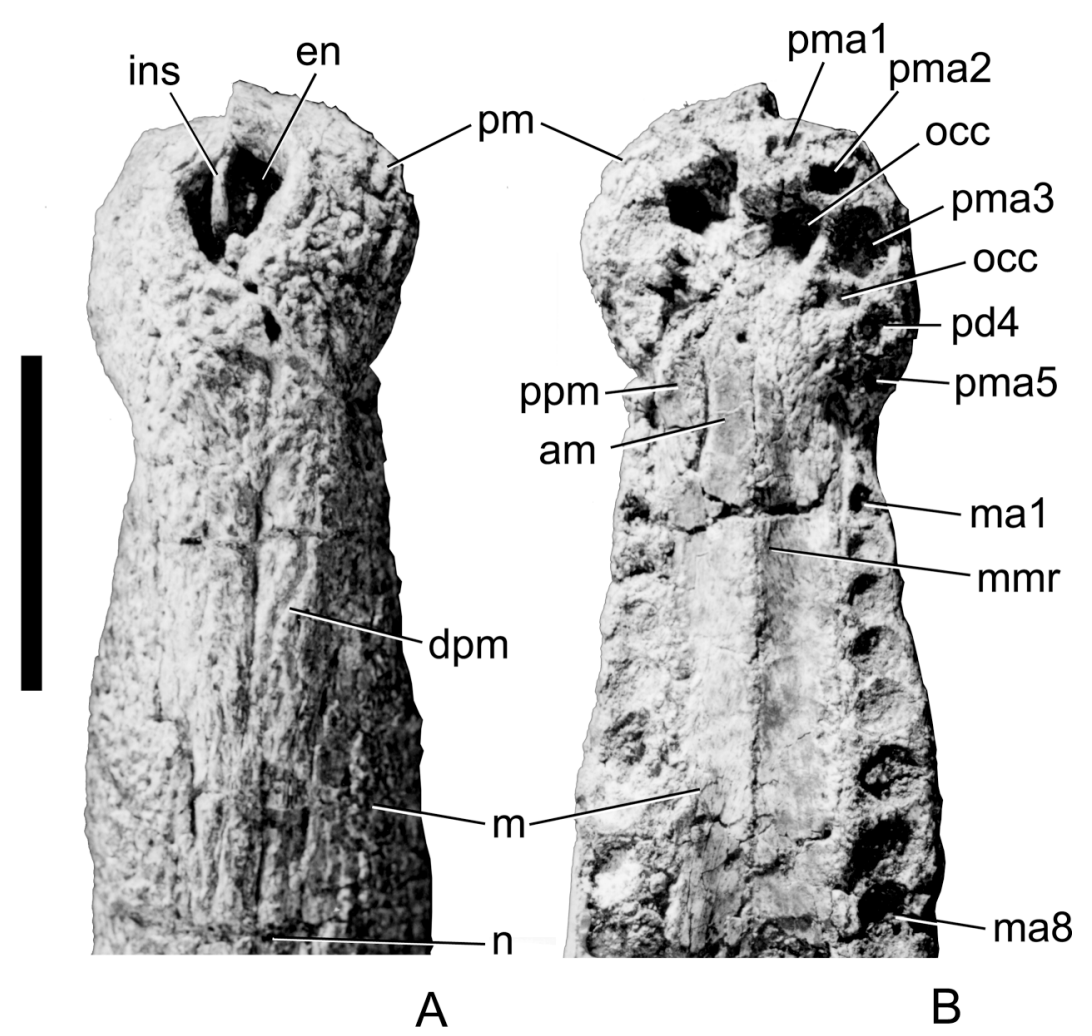

FIGURE 7. Calsoyasuchus valliceps nov. (TMM 43631-1). Photographs of anterior end of rostrum in A, dorsal; and B, ventral views. Right premaxilla is broken and displaced slightly dorsally and anteriorly. Median maxillary ridge drops from palatal surface between the rostral constriction to a plane roughly even with the sixth maxillary alveolus. Abbreviations in text. Scale bar equals $5 \mathrm{~cm}$.

broken tip of a replacement tooth protrudes through the older tooth base near the medial edge of this alveolus.

The external naris forms a sub-triangular aperture that opens dorsally and slightly anteriorly (Fig. 7A). The naris is partially separated by a spike-like internarial process that angles dorsally from the rear part of the floor of the nasal vestibule. The bone is broken, but CT imagery (Fig. 4, slice 24: COR 017-COR 026) shows this process may be a dorsal extension of the premaxillary palatal processes. This weak division of the naris in Calsoyasuchus represents an apomorphic condition rather than retention of the primitive internarial septum that separates the right and left nares in basal archosaurs. It differs greatly from the internarial septum present in some members of extant Crocodylia (Osteolaemus tetraspis, Alligator mississppiensis, A. sinensis; Iordansky, 1973; Rowe et al., 1999a, b), in which the bar is formed from paired anterior processes of the nasals and short posterior processes of the premaxillae.

Laterally, the premaxilla meets the maxilla with a strong suture within the rostral constriction. Dorsally, the premaxillae meet behind the naris, excluding the nasals from the narial aperture. Flat dorsal processes of the right and left premaxillae extend posteriorly between the maxillae, to meet the nasals at a plane even with the eighth maxillary alveoli.

Each premaxilla bears a large paramedian occlusal pit just behind the anterior alveoli (Fig. 4, slice 24; Fig. 7B). This excavation probably received the tip of an enlarged symphyseal dentary tooth. A second, smaller occlusal pit lies posterolateral to the first, between and medial to the third and fourth premaxillary alveoli. A third smaller occlusal pit lies posteromedial to the fifth alveolus of the left premaxilla. There is no evidence of an incisive foramen, but breakage and displacement of the right premaxilla renders interpretation of this area ambiguous. The premaxillary palatal processes separate just posterior to the large anterior occlusal pits, and are divided by anterior processes of the maxillae (Fig. 2D). The premaxilla-maxilla suture extends posterolaterally from the palatal midline, then angles anteriorly through the third occlusal pit to almost reach the fifth premaxillary alveolus. From there the suture travels dorsally, through the rostral constriction and onto the roof of the snout. Coinciding with the constriction at the premaxilla-maxilla contact is an interruption in the tooth row. There is no laterally open gap in the snout at this junction and the surface is faintly sculptured in the constriction, contrasting with the condition in basal crocodylomorphs, protosuchids, and the Fruita taxon (Crompton and Smith, 1980; Clark, 1986, 1994; Walker, 1990; Wu et al., 1997).

Maxilla - The maxilla is long and low, and it forms most of the elongated rostrum. Its posterior extent is indeterminable owing to breakage and erosion. As described above, the maxilla is rigidly attached to the premaxilla, and dorsally it meets the posterodorsal process of the premaxilla and the nasal along simple contacts. A small dorsal process forms the anterior and part of the dorsal border of the external antorbital fenestra. The dorsal process meets the nasal just above the rim of the external antorbital fenestra and it meets the lacrimal within the fenestra. Ventral to the fenestra the maxilla is overlapped by the jugal (Fig. 4, slice 279). As in other archosaurs with a fenestrated snout, the bone texture within the antorbital fossa is smooth, contrasting with the sculpturing over most of the rest of the external skull surface.

The maxilla extends posteriorly beyond the antorbital fenestra, and there bifurcates into a dorsal ramus that borders the orbit medial to the jugal and a ventral ramus that contains the alveoli. The orbital ramus can be seen in the anteroventral rim of the orbit only in ventral and medial views, being hidden by the overlapping lacrimal and jugal in lateral view. The alveolar 
ramus, which is incomplete on both sides, extends posteriorly at least as far as a plane almost even with the anterior margin of the orbit. The jugal does not split the two maxillary rami, but rather overlaps them and walls in an internal medial fossa (Fig. 1A, B)

The lateral surface of the maxilla is marked by an irregular depression anteroventral to the antorbital fenestra and just dorsal to the alveolar border (Fig. 1A, D). The texture within the depression is smoother than the surrounding maxillary surface, and within the depression are several smaller fossae. The depression's posterior edge is even with the anterior rim of the internal antorbital fenestra.

The maxillae form most of the osseous secondary palate (Fig. $2 \mathrm{C}, \mathrm{D})$. From the rostral constriction, each maxilla sends a medial palatal process forward and together they broadly separate the right and left premaxillary palatal processes. The maxillary palatal processes curve ventrally to meet along the midline in the vicinity of the rostrum constriction, forming a median ridge on the palatal surface that descends below the alveolar border (Figs. 1B, D, 7B). The palatal processes are flat for a short distance posterior to the sixth alveoli, before arching posterodorsally towards the primary choanae and the nasopharyngeal duct.

Each maxillary palatal process divides to form the anterior border of the primary choana. One ramus diverges medially, where it rises toward the midline to meet the vomer and anterior process of the pterygoid in the roof of the nasopharyngeal duct. This contributes to the separation of the right and left primary choanae (Fig. 8A, B). The other ramus diverges laterally and, flanking the palatine, forms the lateral portion of the palatal shelf. The palatine thus excludes the maxillary lateral ramus from the nasopharyngeal duct.

There are at least 29 alveoli present in the more complete left maxilla, but the full dental count is unknown. The first alveolus is the smallest in the maxilla, and alveolar diameter increases gradually until the eighth alveolus. The fifth through eighth alveoli are the largest in the maxilla, which swells slightly outward around them. CT images show that these alveoli are also the deepest in the maxilla and that they arc posteriorly within the bone (Fig. 5, slice 48: SAG 037-055; HOR 055-075), also an indication that they held the longest teeth in maxilla. From the ninth tooth position posteriorly, the alveoli decrease progressively in diameter. The more posterior teeth have shallower implantations that lie beneath the caviconchal recess (see below).

The only maxillary teeth preserved and visible in external view are a broken right 11th maxillary tooth, the base of the right 21 st maxillary tooth, and the barely visible base of the left ninth maxillary tooth. The partial crown of the 11th maxillary tooth is split just labial to its meso-distal axis. The crown is short and displays little labio-lingual compression. Both mesial and distal edges bear fine serrations.

Nasal-The nasal interdigitates with the dorsal process of the premaxilla near the plane through the 8th maxillary alveoli. It broadens toward the orbit and is divided posteriorly by the prefrontal. The medial process twists on its long axis, sloping toward the midline and forming the deep dorsal valley on the skull roof (Figs. 2A, B, 9). The degree of slope increases posteriorly, deepening the median depression to a point just anterodorsal to the orbits. Here the surfaces of the nasals and the frontal are nearly vertical, and the opposing sides pinch to contact at one point on the frontal (COR 317). The nasofrontal suture lies within the valley, just anterior to its deepest point The valley shallows posteriorly and disappears between the orbits. Other crocodyliforms such as Theriosuchus (Clark, 1986), Hsisosuchus (Li et al., 1994) and some thalattosuchians have a median depression or groove on the nasals and frontal, but not as deep as in Calsoyasuchus. The lateral process of the nasal meets the anterior and dorsomedial edges of the lacrimal above the external antorbital fenestra. The nasal laterally contacts the maxilla along most of its length. The nasal bones meet each other medially along a simple edge to edge contact.

Prefrontal-The prefrontal is a wedge-shaped bone that forms the anterodorsal quarter of the orbital rim, where it meets the frontal and lacrimal. Its pointed anterior tip extends forward to a point almost even with the anterior margin of the internal antorbital fenestra, splitting the posterior end of the nasal. Although no palpebral bones were found with the specimen, a single faint facet marks the articulation of at least one palpebral along the upper margin of the orbit. Impressions of short but broad prefrontal pillars (=descending process of prefrontal) were preserved in matrix ventral to the interorbital region of the skull roof. It is impossible to tell whether the prefrontal pillars contacted the palatines.

Lacrimal-The lacrimal is a dorsoventrally short bone with a deeply excavated lacrimal antorbital fossa on its anterior and lateral surfaces (Figs. 1, 9). The lacrimal meets the maxilla within the external antorbital fenestra and anteriorly it meets the nasal. It also meets the prefrontal dorsally. The lacrimal forms most of the dorsal and posterior border of the internal antorbital fenestra. Its medial surface bears a deep recess between the internal antorbital fenestra and orbit that may have held the lacrimal gland or pneumatic tissue in life. A small foramen connects the deep medial fossa and the lateral surface of the lacrimal. The nasolacrimal canal originates dorsal to this median fossa and passes anteriorly through the lacrimal, exiting through the medial surface of the bone above the internal antorbital fenestra (COR 331-293). Ventrally the lacrimal meets the jugal and maxilla, overlapping the latter.

Jugal-The anterior and posterior borders of the jugal are not well defined, owing to poor preservation. The jugal extends anteriorly beneath the external antorbital fenestra and sends a small triangular flange into the antorbital fenestra. The jugal is bordered dorsally by the lacrimal, and ventrally and anteriorly by the maxilla. The jugal overlaps divergent posterior rami of the maxilla laterally, spanning the space between these processes and forming the lateral wall of a large medial fossa (Figs. 1A, B, 4, slice 313). Medially, the jugal meets the dorsal maxillary ramus in the anteroventral corner of the orbit, contributing to the suborbital bar. A remnant of the broken dorsal (=postorbital) process exhibits very faint pits and grooves, and it ascends the anteriolateral edge of the postorbital bar.

Frontal - On its dorsal surface the frontal appears to be a single element, an apomorphic condition shared with the Fruita taxon and all other adult mesoeucrocodylians (Clark, 1986, 1994; Benton and Clark, 1988). CT imagery indicates that the frontal arose in ontogeny as a pair of bones that were not completely fused at time of death; a persistent, faint median suture between the two is discernible ventrally (COR 317-374). The anterior (=nasal) process of the frontal meets the nasal within the skull's median dorsal valley (Figs. 2A, B, 9). The dorsal surface of the frontal is flat posterior to the valley. The frontal broadens to meet the frontal processes of the postorbital posterior to the orbits. The frontal does not contribute to the border of the supratemporal fenestra. Dorsally the frontal meets the parietal between the anterior rims the supratemporal fenestrae. The frontal continues posteriorly deep to the parietal, extending between the supratemporal fenestrae. The pineal fossa forms a rounded pit in the ventral surface of the frontal, just anterior to the fronto-parietal junction. It does not penetrate to the surface. From the dorsal rim of the orbit the frontal curves ventromedially. The bone is deeply grooved ventrally between the orbits, marking the path of the olfactory tract.

Parietal-There is a single median parietal element and all but its posterior edge is preserved. The parietal forms the medial border of the small supratemporal fenestrae. A thin antero- 

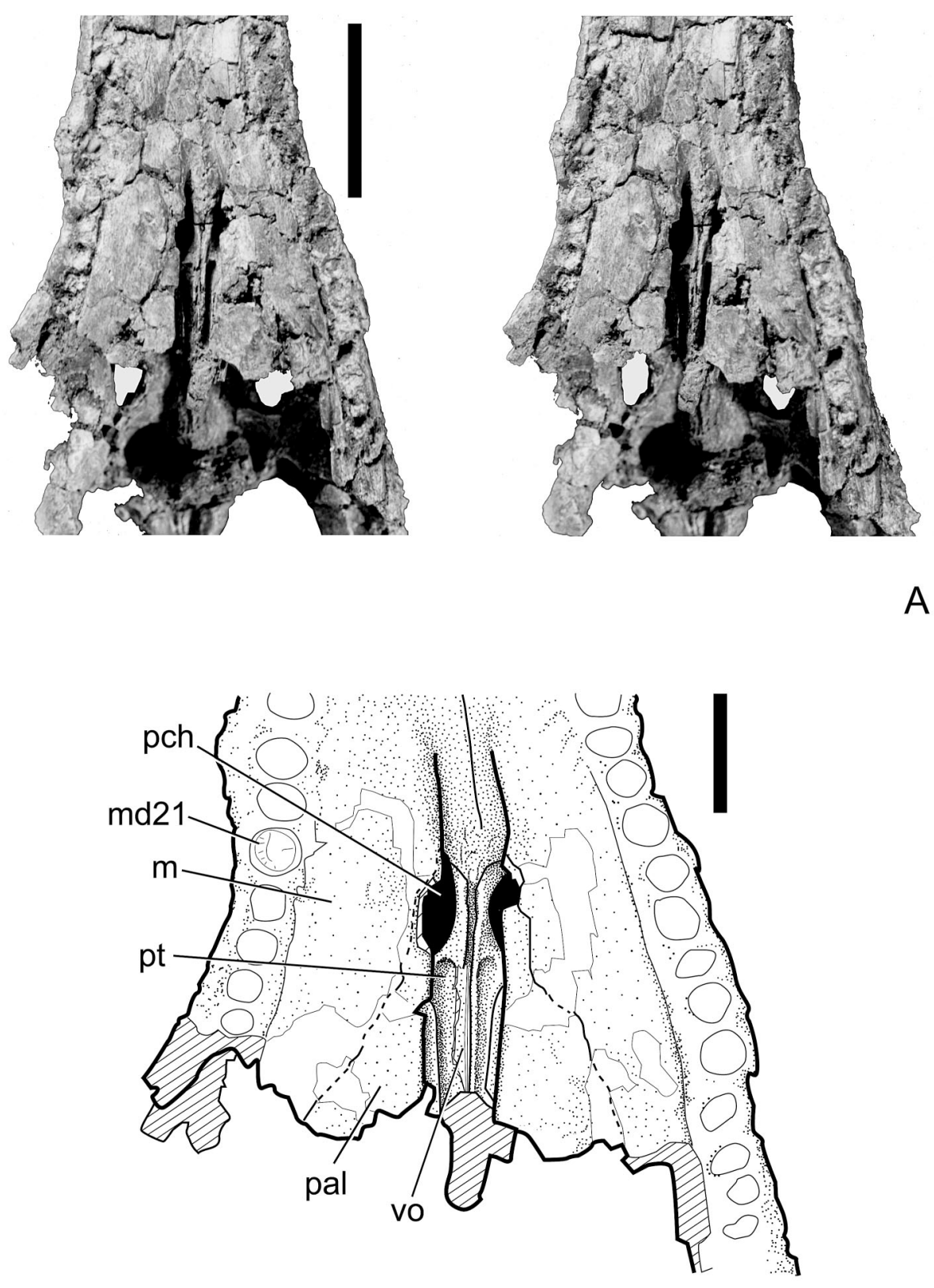

FIGURE 8. Calsoyasuchus valliceps nov. (TMM 43631-1). A, stereophotograph pair focusing on palatal shelves, primary choanae, and nasopharyngeal duct. B, labeled drawing of posterior palate, with detail of bones roofing the nasopharyngeal duct. Cross hatched areas indicate broken bone. Non-stippled areas represent missing surface bone or cracks. Abbreviations in text. A, scale bar equals $5 \mathrm{~cm}$. B, scale bar equals $2 \mathrm{~cm}$.

lateral process contacts the postorbital, thereby excluding the frontal from the supratemporal fenestra. Between the fenestrae the parietal is flat and deeply sculptured, and it broadens to meet the squamosal. It is unknown how much the parietal contributes to the occiptial surface of the skull. The endocranial surface of the parietal is embossed with a shallow impression of the dorsal surface of the brain.

Postorbital-Most of the left postorbital is present, although its anterodorsal corner is poorly preserved. The ventral (=jugal) process descends medial to the dorsal process of the jugal. The lateral surface of the process is marked by a small round depression but otherwise it is not sculptured. However, the broken dorsal process of the jugal exhibits faint pits and grooves. The postorbital bar is very thick in section, and is inset slightly beneath the skull table (COR 376-393). As the bar descends, it curves laterally to meet the posterior ramus of the jugal. The postorbital meets the squamosal posteriorly on the skull table. This contact continues around the lateral margin of the skull table.

Quadrate - Only the anterodorsal end of the left quadrate is present in the specimen, where it meets the postorbital and squamosal. The quadrate contact with the postorbital is a feature shared with other crocodyliforms. There is no trace of the quadratojugal.

Squamosal-Pieces of both squamosals are present. The left squamosal meets the postorbital anteriorly and the quadrate 

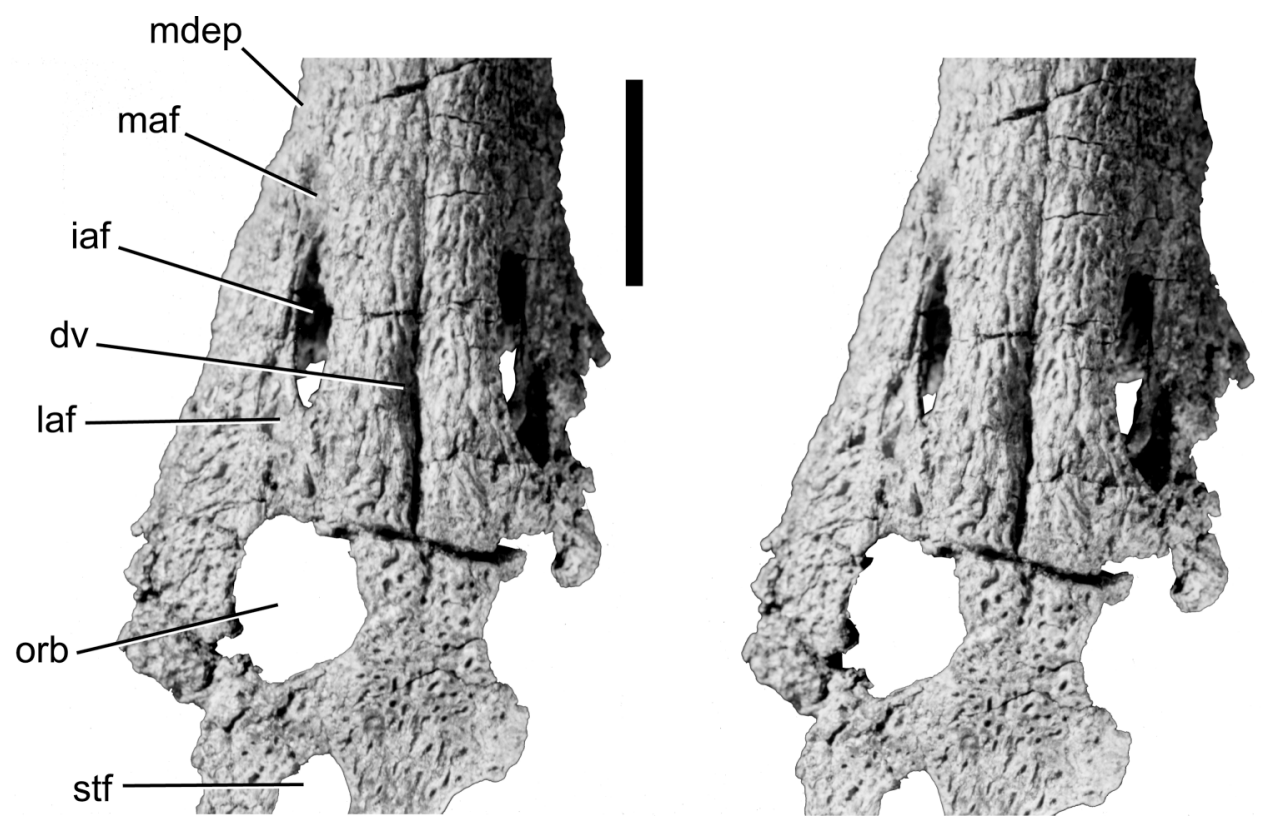

FIGURE 9. Calsoyasuchus valliceps nov. (TMM 43631-1). Stereophotograph pair of skull dorsal surface from the antorbital fenestrae to middle of supratemporal fenestrae. Abbreviations in text. Scale bar equals $5 \mathrm{~cm}$.

ventrally. The remaining part of the right squamosal meets the parietal posterior to the supratemporal fenestra. The flat dorsal surface of the squamosal contributes to the skull table.

Palatine - The palatine is divided into two distinct laminae or processes. A medial process of elaborate architecture rises upwards into the nasophayrngeal duct. It forms most of the lateral border of the primary choana. Posterior to the choana, a curved dorsal palatine lamina forms the wall and lateral part of the roof of the nasopharyngeal duct. The dorsal lamina curves medially to meet the anterior process of the pterygoid on the roof of the nasopharyngeal duct, along an abutting contact that forms a parasagittal ridge which projects down into the duct (Fig. 4, slice 279: COR 265-284). The palatal process of the palatine is narrow anteriorly and widens posteriorly. It forms the medial surface of the palatal shelf, excluding the maxilla from the nasopharyngeal duct (Figs. 2C, D, 8A, B).

Pterygoid - Only the anterior palatal process of each pterygoid is preserved. The anterior process is a very thin bar that contacts the vomer dorsally and the maxilla anteriorly in the roof of nasopharyngeal duct. Along the midline, the anterior processes separate the right and left primary choanae (Fig. 8A, B). Toward the front of the choanae, these processes clasp the posterior median processes of the maxillae. Further posteriorly, each process widens into a thin plate that forms the posterior border of the primary choana and medial part of the roof of the nasopharyngeal duct. This thin process is strongly convex dorsally, forming a deep parasagittal arch (Figs. 4, slice 279; 8A, B: COR 261-290).

Vomer-Only a thin splint of the vomer is visible in ventral view, between the anterior processes of the pterygoids; most information about this bone was provided by the CT imagery. The vomers appear to be unfused. Each forms a longitudinal bar that rises from the floor of the nasal cavity (HOR 063-075). The vomers may originate as far forward as the anterior margins of the primary choanae (COR 234; HOR 68). In this area they together form a median U-shaped trough along the floor of the nasal cavity. The vomers become thinner and straighter posteriorly, forming a Y-shaped bony brace dorsal to and be- tween the long anterior processes of the pterygoids in the roof of the nasopharyngeal duct (Fig. 4, slice 279: COR 259-296).

Nasal Cavity and Paranasal Maxillary Cavities-CT imagery reveals that the maxilla forms most of the bony tubular walls of the nasal cavity (COR 033-245). The maxilla is also excavated by an extensive array of pneumatic paranasal cavities, similar to the condition in extant Crocodylia (Wegner, 1958; Witmer, 1995; Rowe et al., 1999a, b). The nasal cavity is a long, median, bone-enclosed tube that connects the nasal vestibule with the primary choana. The cavity is conical, its diameter almost doubling from the nasal vestibule posteriorly to the primary choana, and it fills roughly $20 \%$ of the volume of the rostrum. The cavity is roofed by the flat dorsal processes of the premaxilla back to near the 8th maxillary alveolus, and by the nasals posterior to that. A descending process from the nasal may form part of the dorsolateral wall of the nasal cavity.

The postvestibular recess (Witmer, 1995) extends anteriorly as far as above the 11th alveolus and terminates posteriorly dorsal to the caviconchal recess, above alveolus 15 or 16 (Fig. 4, slice 156: COR 155-188; SAG 039-050, 074-081; HOR 064073). The recess is more posteriorly located than in extant Crocodylia (Witmer, 1995:fig. 12C, B), but this may be a result of the relative elongation of the snout in Calsoyasuchus. The recess is entirely dorsal and medial to the alveoli. The postvestibular recess opens directly into the nasal cavity through a ventrally directed aperture (COR 172-183; HOR 066-068 [left side], 070-073 [right side]).

A triangular cavity, the cavioconchal recess (Witmer, 1995), excavates the maxilla posterior to the postvestibular recess (Fig. 4, slice 201: COR 155-240; SAG 028-049, 074-086; HOR 054073). The cavioconchal recess also remains dorsal to the alveoli and expands posteriorly as the snout becomes wider (Fig. 4, slice 201: COR 118-257; SAG 027-050, 071-089). The recess is subdivided into chambers that are more or less separated from each other by thin, incomplete transverse septa (Fig. 6, slice 67). The most posterior subchamber opens through the caviconchal aperture into the posterior end of the nasal cavity, near the primary choana. 


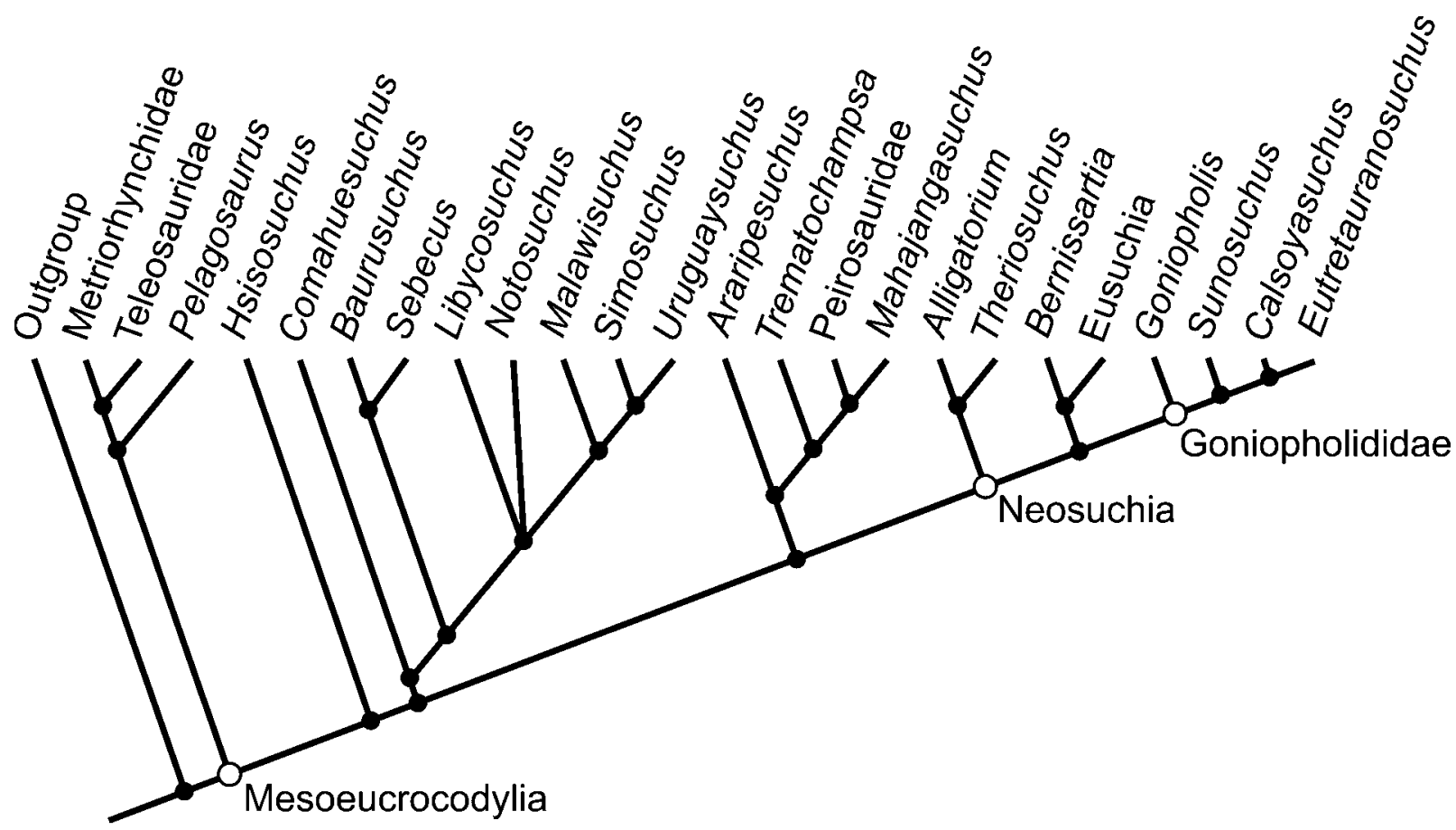

FIGURE 10. Strict consensus cladogram of 3 equally most parsimonious trees generated by this analysis. In three different analyses, tree length ranged from 262 to 264 steps (see text for other statistics). Outgroups are Protosuchus, Hemiprotosuchus, and Orthosuchus.

Longitudinal accessory cavities (Witmer, 1995) pass through the maxillary palatal processes, beneath the nasal cavity (Fig. 4, slices 90, 156, 201; Fig. 5, slices 48, 57, 69: COR 047-221, SAG 040-077, HOR 061). Each originates from the caviconchal recess, near the primary choanae and passes anteriorly through the length of the palatal process of the maxilla (COR 046-231), where they end blindly. The accessory cavities produce a double-walled secondary palate similar to that described for Crocodylia (Wegner, 1958; Witmer, 1995).

A third set of pneumatic cavities extends into the lateral palatal shelf of the maxilla, which is 'honeycombed' by several small interconnecting cavities (Fig. 4, slice 279: COR 224-301). They evidently communicated with the nasal cavity in front of the choana. It is not clear whether this set of recesses is homologous to the caudolateral recess associated with the palatine bone of Crocodylia. At this time it cannot be determined if these cavities communicated directly with the nasal cavity or via some other recess. Until their exact affinities and homologies are established we tentatively and collectively refer to these as secondary accessory cavities. The palatine is variably pneumatized in several extant taxa (Wegner, 1958; Witmer, 1995) but the preserved portions appear to be apneumatic in Calsoyasuchus.

The osseus canal for the maxillary branch of the trigeminal nerve (V) can be easily traced through the body of the maxilla from as far anteriorly as the second maxillary alveolus to just anterior to the primary choana (COR 081-229). The bony canal for the maxillary nerve remains dorsolateral to the alveoli in the anterior and middle parts of the snout (Fig. 4, slices 90, 156), but shifts to a relatively more lateral position posteriorly (Fig. 4, slice 201). The diameter of the canal increases in the vicinity of alveoli $11-14$. The passage remains ventrolateral to the postvestibular and caviconchal recesses.

\section{DISCUSSION}

All three of our phylogenetic analyses resulted in three equally most parsimonious trees (Fig. 10), which differed only in the relative positions of Libycosuchus and Notosuchus. The tree topology is essentially the same as found by Buckley et al. (2000), from which the character matrix was adapted. Diagnoses for the taxa found in our analyses varied slightly when certain characters were treated as ordered (see Methods). The diagnoses presented below are based on the analysis in which all characters were treated as un-ordered, but the findings of the other two analyses are noted below as equivocal characters.

All of our analyses found weak but unambiguous support for a monophyletic Goniopholididae consisting of Goniopholis, $\mathrm{Su}$ nosuchus, Calsoyasuchus, and Eutretauranosuchus. The clade is unambiguously diagnosed by the following: the nasal does not take part in the narial border; the choana is divided by a septum; and by a distinctive depression on the lateral surface of the maxilla. An equivocally diagnostic character involves the palatal rami of the premaxillae, which meet posteriorly along their contact with the maxillae. Some of these characters are also independently present in non-goniopholidid taxa.

Although occurring later in time, Goniopholis was found to be the sister taxon to the other goniopholidids. Sunosuchus, Calsoyasuchus, and Eutretauranosuchus are united unambiguously by secondary choanae (sensu Witmer, 1995) that are more than three times longer than wide. These three taxa are also equivocally united by the presence of one large palpebral bone, and by the presence of the mandibular fenestra.

The less-inclusive goniopholid clade comprising Calsoyasuchus and Eutretauranosuchus is diagnosed by palatines that form palatal shelves that do not meet; and by long anterior processes of the pterygoids that contact the maxillae anteromedial to the primary choanae. This clade is equivocally diagnosed by an antorbital fenestra that is no more than half the size of the orbit (much smaller in E. delfsi).

The skull of Calsoyasuchus compares closely with the type specimen of "Goniopholis" felix (YPM 517, =Diplosaurus felix Marsh), and with an uncatalogued goniopholid from Dinosaur National Monument, referable to Eutretauranosuchus delfsi (pers. obs.). The skull of "Goniopholis" felix exhibits similar 


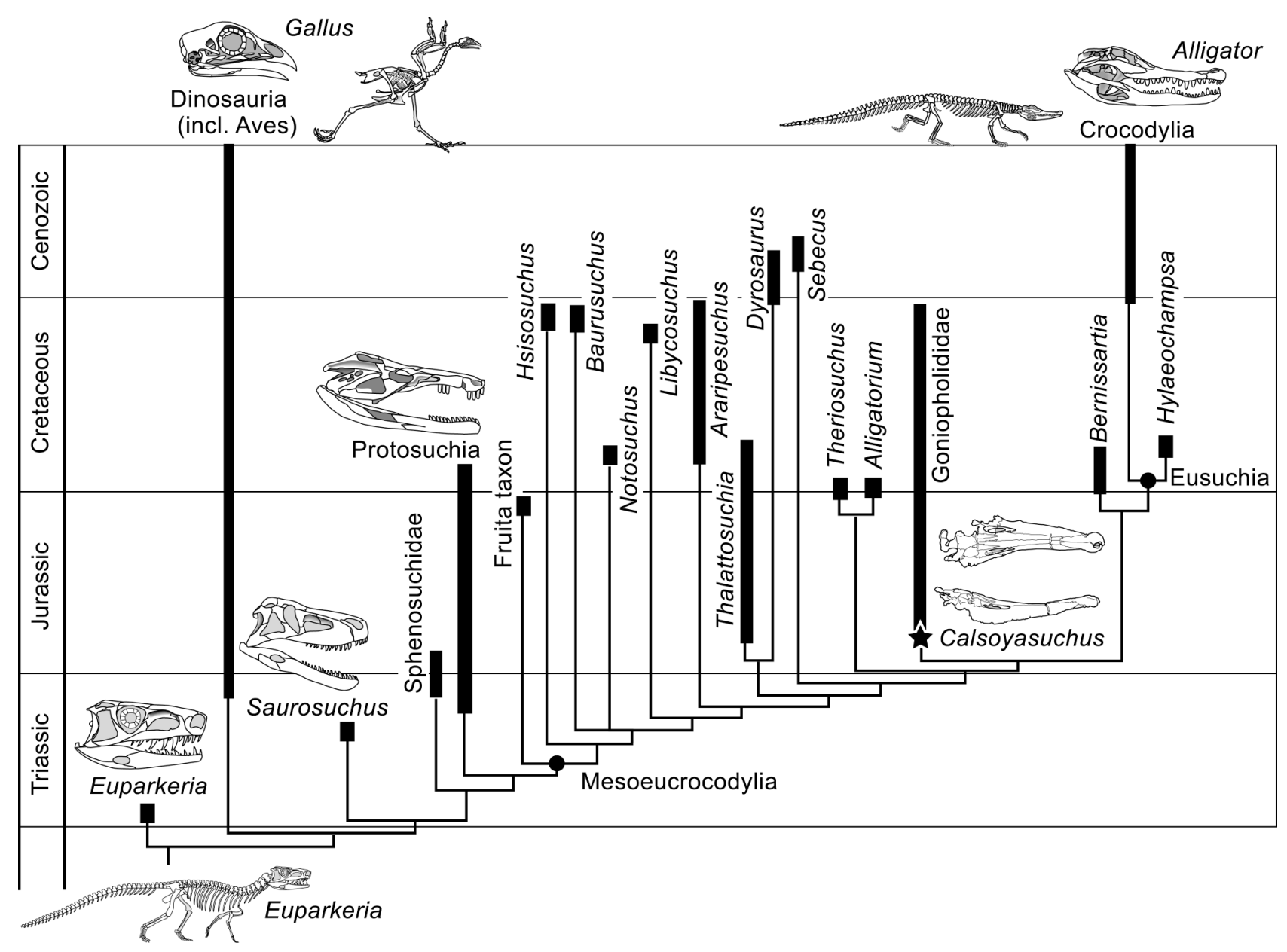

FIGURE 11. Phylogenetic relationships of the crocodyliform taxa analyzed in this report, superimposed upon the geologic time scale. Heavy lines indicate the geologic ranges of lineages represented by fossils; thin lines represent inferred history (ghost lineages) based on the phylogenetic analysis (Fig. 10).

downward and upward bowing that elevates the rostrum tip to a level almost even with the skull table. The retention of an antorbital fenestra, albeit very small, in the Dinosaur National Monument specimen and possibly also in "Goniopholis" felix may represent reduction of a Calsoyasuchus-like antorbital fenestra. The long, tapered snout of Calsoyasuchus more closely resembles the sleder-snouted goniopholids such as Sunosuchus and Vectisuchus leptognathus than relatively broad-snouted goniophholids (e.g., Goniopholis simus) (Buffetaut and Hutt, 1980; Wu et al., 1996). These resemblances suggest that as a more complete fossil record of goniopholidids becomes known, reanalysis of the clade may alter the relationships found in our preliminary analyses, and that Calsoyasuchus may eventually find a more basal position among goniopholidids.

The Calsoyasuchus type specimen provides a clear view of the primary choanae, the nasopharyngeal duct, and the surrounding bones, a luxury not always available in such ancient crocodyliforms. The nasopharyngeal duct is open ventrally in both Calsoyasuchus and Eutretauranosuchus. It was first reported that the palatines of $E$. delfsi contact each other, resulting in anterior and posterior choanal openings in the palate (Mook, 1967), but later work demonstrated a separation between the palatines in this taxon (Langston (1973: fig. 6C). The wellpreserved Dinosaur National Monument $E$. delfsi confirms that the palatines closely approach on the midline, but do not actually contact each other nor the anterior processes of the pter- ygoids. The exact position of the primary choana is unknown in $E$. delfsi because the nasopharyngeal duct is filled with matrix in both the type (CMNH 8028) and Dinosaur National Monument specimens. The long anterior processes of the pterygoids contact the maxillae in both taxa, dividing the nasopharyngeal duct. Both taxa differ from Sunosuchus, in which the palatines are in broad contact medially, resulting in a pair of anteriorly placed palatal openings and posteriorly positioned but elongated secondary choanae (Wu et al., 1996:fig. 4B).

This analysis finds the goniopholidid clade to be the sister taxon of an unnamed lineage consisting of Eusuchia + Bernissartia. The Early Cretaceous taxon Bernissartia is currently the oldest known member of that lineage. Teeth and osteoderms from Middle Jurassic (Bathonian) deposits of England were referred to Goniopholididae (Evans and Milner, 1994), but insofar as there are no dental apomorphies of the clade these referrals can be only tentative. Diagnostic goniopholidid remains are known from Late Jurassic through Late Cretaceous sediments.

Calsoyasuchus extends goniopholidid history into the Early Jurassic (Sinemurian-Pliensbachian), and by implication the range of its sister lineage as well. The new specimen substantially increases the length of the goniopholidid fossil record, and suggests that the unnamed eusuchian stem lineage is far older than its currently known fossil record indicates (Fig. 11). Moreover, goniopholidids share a closer ancestry with Eusuchia than several clades currently known exclusively from Creta- 
ceous and Paleocene fossil records. Contrary to the popular view that crocodyliforms possess an exceptionally complete record (e.g., Markwick, 1998), our phylogenetic analysis suggests that the crocodyliform Mesozoic fossil record is still punctuated by large gaps.

Calsoyasuchus valliceps is the fifth crocodylomorph collected from the silty facies of the Kayenta Formation of northeastern Arizona (Clark, 1986; Clark and Fastovsky, 1986; Sues et al., 1994). Until now, wide temporal and morphological gaps separated Late Jurassic and younger crocodyliformes from the archaic protosuchian-grade taxa of the Triassic and Early Jurassic. Calsoyasuchus is transitional in both time and morphology. Although plesiomorphic in retaining an external antorbital fenestra and a ventrally open nasopharyngeal duct, Calsoyasuchus is surprisingly derived in other respects such as its extensive system of paranasal pneumatic cavities in the snout and palate, which compares very closely with that present in extant crocodylians.

\section{ACKNOWLEDGMENTS}

We thank the Navajo Nations Minerals Department for granting us permits to work and collect on lands of the Navajo Nation. We also thank Farish A. Jenkins, Jr. (MCZ) for invaluable assistance throughout this project. We are indebted to Dr. Kyril Calsoyas of Seba Dalkai School for his advice, assistance, and hospitality during our visits to Arizona. We thank Mr. Tommy Anderson, Director of the Navajo Eco-Scouts, for help during all phases of our work. We are grateful to the many members of the Joe, Manygoats, Nez, and Yazzi clans, who have allowed us to share the spectacular beauty of their land, and to $\mathrm{Mr}$. Harry Manygoats, for sharing much of its history with us. We are deeply grateful to Dr. Wann Langston, Jr., Dr. Jim Clark, and Dr. Chris Brochu for generous access to unpublished notes, manuscripts, specimens, and for freely sharing their encyclopedic knowledge of extinct crocodylomorphs. Mr. Chuck Schaff (MCZ) and Dr. John Merck, Jr. helped collect the type specimen and provided transcendental advice throughout our field season. Dr. Pamela Owen provided assistance with catalog and collection issues. This work was supported by the Langston and Lowe funds of the Geology Foundation of The University of Texas at Austin, and National Science Foundation grant IIS 9874781.

\section{LITERATURE CITED}

Attridge, J., A. W. Crompton, and F. A. Jenkins, Jr. 1985. The southern African Liassic prosauropod Massospondylus discovered in North America. Journal of Vertebrate Paleontology 5:128-132.

Benton, M. J., and J. M. Clark. 1988. Archosaur phylogeny and the relationships of the Crocodylia; pp. 295-338 in M. J. Benton (ed.), The Phylogeny and Classification of the Tetrapods, Vol. 1. Amphibians, Reptiles, Birds. Systematics Association Special Volume No. 35A. Clarendon Press, Oxford.

Brochu, C. A. 1997a. Morphology, fossils, divergence timing, and the phylogenetic relationships of Gavialis. Systematic Biology 46:479_ 522.

- - - 1997b. A review of "Leidyosuchus" (Crocodyliformes, Eusuchia) from the Cretaceous through Eocene of North America. Journal of Vertebrate Paleontology 17:679-697.

- - - 1999. Phylogenetics, taxonomy, and historical biogeography of Alligatoroidea; pp. 9-100 in T. Rowe, C. A. Brochu, and K. Kishi (eds.), Cranial Morphology of Alligator and Phylogeny of Alligatoroidae. Society of Vertebrate Paleontology Memoir 6, Journal of Vertebrate Paleontology 19, supplement to number 2.

Buckley, G. A., and C. A. Brochu. 1999. An enigmatic new crocodile from the Upper Cretaceous of Madagascar; pp. 149-175 in D. Unwin (ed.), Cretaceous Terrestrial Vertebrates. Special Papers in Palaeontology, No. 60.

- - , C. A. Brochu, D. W. Krause, and D. Pol. 2000. A pug-nosed crocodyliform from the Late Cretaceous of Madagascar. Nature 405:941-944.
Buffetaut, E., and S. Hutt. 1980. Vectisuchus leptognathus, n.g. n. sp., a slender-snouted goniopholid crocodilian from the Wealden of the Isle of Wight. Neues Jahrbuch für Geologie und Paläeontologie Monatshefte 1980:385-390.

Clark, J. M. 1986. Phylogenetic relationships of the crocodylomorph archosaurs. Ph.D. dissertation, University of Chicago, Chicago, 556 pp.

- - - 1994. Patterns of evolution in Mesozoic Crocodyliformes; pp. 84-97 in N. C. Fraser and H.-D. Sues (eds.), In the Shadow of the Dinosaurs: Early Mesozoic Tetrapods. Cambridge University Press, Cambridge.

- - - , and D. E. Fastovsky. 1986. Vertebrate biostratigraphy of the Glen Canyon Group in northern Arizona; pp. 285-301 in K. Padian (ed.), The Beginning of the Age of Dinosaurs: Faunal change across the Triassic-Jurassic boundary. Cambridge University Press, Cambridge.

- - - , and M. Norrell. 1992. The Early Cretaceous crocodylomorph Hylaeochampsa vectiana from the Wealden or the Isle of Wight. American Museum Novitates 3032:1-19.

Colbert, E. H. 1981. A primitive ornithischian dinosaur from the Kayenta Formation of Arizona. Bulletin of the Museum of Northern Arizona 53:1-61.

Crompton, A. W., and K. K. Smith. 1980. A new genus and species of crocodilian from the Kayenta Formation (Late Triassic?) of Northern Arizona; pp. 193-217 in L. L. Jacobs (ed.), Aspects of Vertebrate History: Essays in Honor of Edwin Harris Colbert. Museum of Northern Arizona Press.

- - - , and Z. Luo. 1993. Relationships of the Liassic mammals Sinoconodon, Morganucodon, and Dinnetherium; pp. 30-62 in F. S. Szalay, M. J. Novacek, and M. C. McKenna (eds.), Mammalian Phylogeny. Springer-Verlag, New York.

Evans, S. E., and A. R. Milner. 1994. Middle Jurassic microvertebrate assemblages from the British Isles; pp. 303-321 in N. C. Fraser and H.-D. Sues (eds.), In the Shadow of the Dinosaurs: Early Mesozoic Tetrapods. Cambridge University Press, Cambridge.

Gaffney, E. S., J. H. Hutchinson, F. A. Jenkins, Jr., and L. J. Meeker. 1987. Modern turtle origins: the oldest known cryptodire. Science 237:289-291.

Harshbarger, J. W., C. A. Repenning, and J. H. Irwin. 1957. Stratigraphy of the uppermost Triassic and Jurassic rocks of the Navajo country. United States Geological Survey Professional Paper 291:1-74.

Iordansky, N. N. 1973. The skull of the Crocodilia; pp. 201-262 in C. Gans and T. S. Parsons (eds.), Biology of the Reptilia, Vol. 4. Moprhology D. Academic Press, London.

Jenkins, F. A., Jr., A. W. Crompton, and W. R. Downs. 1983. Mesozoic mammals from Arizona: new evidence in mammalian evolution. Science 222:1,233-1,235.

- - - and N. H. Shubin. 1998. Prosalirus bitis and the anuran caudopelvic mechanism. Journal of Vertebrate Paleontology 18:495510 .

- - - , and D. M. Walsh. 1993. An Early Jurassic caecilian with limbs. Nature 365:246-250.

Juricic, D., and R. E. Barr. 1996. Extending engineering design graphics laboratories to have a CAD/CAM component: implementation issues. Engineering and Design Graphics Journal 60:26-41.

Kermack, D. M. 1982. A new tritylodontid from the Kayenta Formation of Arizona. Zoological Journal of the Linnean Society 76:1-17.

Ketcham, R. A., and W. D. Carlson. 2001. Acquisition, optimization, and interpretation of X-ray computed tomographic imagery: applications to the geosciences. Computers \& Geosciences 27:381-400.

Langston, W. 1973. The crocodilian skull in historical perspective; pp. 263-284 in C. Gans and T. S. Parsons (eds.), Biology of the Reptilia, Vol. 4. Morphology D. Academic Press, London.

Li, J., X. Wu, and X. Li. 1994. New material of Hsisosuchus chungkingensis from Sichuan, China. Vertebrata PalAsiatica 32:107-126. [Chinese with English translation]

Luo, Z., and X.-C. Wu. 1994. The small tetrapods of the Lower Lufeng Formation, Yunnan, China; pp. 251-270 in N. C. Fraser and H.-D Sues (eds.), In the Shadow of the Dinosaurs: Early Mesozoic Tetrapods. Cambridge University Press, Cambridge.

Markwick, P. J. 1998. Crocodilian diversity in space and time: the role of climate in paleoecology and its implication for understanding $\mathrm{K} /$ T extinctions. Paleobiology 24:470-497.

Mook, C. C. 1967. Preliminary description of a new goniopholid crocodilian. Kirtlandia 2:1-10. 
Padian, K. 1984. Pterosaur remains from the Kayenta Formation (?Early Jurassic) of Arizona. Palaeontology 27:407-413.

Rowe, T. 1989. A new species of the theropod Syntarsus from the Early Jurassic Kayenta Formation of Arizona. Journal of Vertebrate Paleontology 9:125-136.

- - - J. Kappelman, W. D. Carlson, R. A. Ketcham, and C. Denison. 1997. High-Resolution Computed Tomography: a breakthrough technology for Earth scientists. Geotimes 42:23-27.

- - - C. A. Brochu, and K. Kishi (eds.). 1999a. Cranial Morphology of Alligator and Phylogeny of Alligatoroidae. Society of Vertebrate Paleontology Memoir 6, Journal of Vertebrate Paleontology 19, supplement to number 2:1-8.

- - , C. A. Brochu, K. Kishi, J. W. Merck, Jr., M. W. Colbert, E. Saglamer, and S. Warren. 1999b. Alligator: Digital Atlas of the Skull; CD-ROM in Society of Vertebrate Paleontology Memior 6. Journal of Vertebrate Paleontology 19, supplement to number 2.

Shubin, N. H., and F. A. Jenkins. 1995. An early Jurassic jumping frog. Nature 377:49-52.

Sues, H.-D. 1985. First record of the tritylodontid Oligokyphus (Synapsida) from the Lower Jurassic of western North America. Journal of Vertebrate Paleontology 5:328-335.

- - - 1986a. Dinnebitodon amarali, a new tritylodontid (Synapsida) from the Lower Jurassic of western North America. Journal of Paleontology 60:758-762.

- - - 1986b. The skull and dentition of two tritylodontid synapsids from the Lower Jurassic of western North America. Bulletin of the Museum of Comparative Zoology 151:217-268.

- - - J. M. Clark, and F. A. Jenkins, Jr. 1994. A review of the Early Jurassic tetrapods from the Glen Canyon Group of the American Southwest; pp. 284-294 in N. C. Fraser and H.-D. Sues (eds.), In the Shadow of the Dinosaurs: Early Mesozoic Tetrapods, Cambridge University Press, Cambridge.

Swofford, D. L. 1991. PAUP: Phylogenetic Analysis Using Parsimony, version 3.0s. Computer program distributed by the Illinois Natural History Survey, Champagne.

Tykoski, R. S. 1998. The osteology of Syntarsus kayentakatae and its implications for ceratosaurid phylogeny. M.S. thesis, The University of Texas at Austin, Austin, 217 pp.

Walker, A. D. 1990. A revision of Sphenosuchus acutus Haughton, a crocodylomorph reptile from the Elliot Formation (late Triassic or early Jurassic) of South Africa. Philosophical Transactions of the Royal Society of London, B, 257:323-372.

Wegner, R. N. 1958. Die Nebenhölen der Nase bei an Krokodilen. Wissenschaftlichen Zeitschrift der Ernst Moritz Arndt-Universität Greifswald 7:1-39.

Welles, S. P. 1954. New Jurassic dinosaur from the Kayenta Fomation of Arizona. Bulletin of the Geological Society of America 65:591598.

- - - 1970. Dilophosaurus (Reptilia: Saurischia), a new name for a dinosaur. Journal of Paleontology 44:989.

- - - 1984. Dilophosaurus wetherilli (Dinosauria, Theropoda) osteology and comparisons. Palaeontographica Abt. A, 185:85-180.

Witmer, L. M. 1995. Homology of facial structures in extant archosaurs (birds and crocodilians), with special reference to paranasal pneumaticity and nasal conchae. Journal of Morphology 225:269-327.

- - - 1997. The Evolution of the Antorbital Cavity of Archosaurs: A study in Soft Tissue Reconstruction in the Fossil Record with an Analysis of the Function of Pneumaticity. Society of Vertebrate Paleontology Memoir 3, Journal of Vertebrate Paleontology, supplement to number 1:1-73.

Wu, X.-C., and S. Chatterjee. 1993. Dibothrosuchus elaphros, a crocodylomorph from the Early Jurassic of China and the phylogeny of the Sphenosuchia. Journal of Vertebrate Paleontology 13:58-89.

- - - , D. B. Brinkman, and J.-C. Lu. 1994. A new species of Shantungosuchus from the Lower Cretaceous of Inner Mongolia, northern China, with comments on S. chuhsienensis Young, 1961, and the phylogenetic position of the genus. Journal of Vertebrate Paleontology 14:210-229.

- - - D. B. Brinkman, and A. P. Russell. 1996. Sunosuchus junggarensis sp. nov. (Archosauria: Crocodyliformes) from the Upper Jurassic of Xinjiang, People's Republic of China. Canadian Journal of Earth Sciences 33:606-630.

- - - , H.-D. Sues, and Z. M. Dong. 1997. Sichuanosuchus shunanensis, a new? Early Cretaceous protosuchian (Archosauria: Cro- codyliformes) from Sichuan (China), and the monophyly of Protosuchia. Journal of Vertebrate Paleontology 17:89-103.

Received 29 September 1999; accepted 16 October 2001.

\section{APPENDIX 1}

The 119 characters and state assignments used in this phylogenetic analysis are listed below. Characters were modified minimally from those of Buckley et al. (2000) but we note that nearly $20 \%$ of these characters proved uninformative in our analyses. For Eutretauranosuchus, several character states are scored differently than in Buckley et al. (2000), based upon examination of a referred specimen from Dinosaur National Monument, as well as from photographs of and notes concerning the holotype of E. delfsi made available to us by Dr. Wann Langston, Jr. An additional state (2) was added to character 12; Character 42 modified from Buckley et al. (2000). Characters 118 and 119 are new. Coding for character states: 0 (ancestral), 1, 2, and 3 (derived), "?" (state unknown), "N" (not applicable).

We ran three analyses, all of which yielded identical tree topologies (Fig. 10). In the first, all characters were treated as unordered, and uninformative characters were ignored. This yielded three trees of equal length (262 steps, $\mathrm{CI}=0.462, \mathrm{RI}=0.652)$.

1. External surface of cranial and mandibular bones smooth (0) or heavily sculptured with deep grooves and pits (1).

2. Rostrum narrow anterior to orbits, broadening abruptly at orbits (0) or broad throughout (1)

3. Rostrum higher than wide (0), or nearly tubular (1), or wider than high (2).

4. Premaxilla forms at least ventral half of internarial bar (0) or forms little, if any, of internarial bar (1).

5. Premaxilla narrow anterior to naris (0) or broad similar in width to part lateral to naris (1)

6. Dorsal part of premaxilla vertical, naris laterally oriented $(0)$ or dorsal part of premaxilla nearly horizontal, naris dorsolaterally or dorsally oriented (1).

7. Palatal parts of premaxillae do not meet posterior to incisive foramen (0) or meet posteriorly along contact with maxillae (1).

8. Premaxilla loosely overlying maxilla on face (0) or premaxilla and maxilla sutured along butt joint (1).

9. Premaxilla and maxilla with broad contact on face, rostrum does not narrow at contact $(0)$, or broad, laterally open notch between maxilla and premaxilla (1), or rostrum constricted at contact with premaxilla and maxilla, forming narrow slit (2) or rostrum constricted at contact, forming broad, laterally directed concavity (3).

10. Posterior ends of maxillae do not meet on palate anterior to palatines (0) or ends do meet (1).

11. Nasals contact lacrimal (0) or do not (1).

12. Lacrimal contacts nasal along medial edge only (0), or on medial and anterior edges (1), or along anterior edge only (2).

13. Nasal takes part in narial border (0) or does not (1).

14. Nasal contacts premaxilla (0) or does not (1).

15. Descending process of prefrontal does not contact palate $(0)$, or contacts palate (1), or contacts palate in robust suture (2).

16. Postorbital anterior to jugal on postorbital bar (0), or postorbital medial to jugal, (1), or postorbital lateral to jugal (2).

17. Anterior process of jugal as broad as posterior process ( 0 ) or about twice as broad as posterior process (1).

18. Jugal transversely flattened beneath infratemporal fenestra (0) or rod-shaped beneath fenestra (1)

19. Quadratojugal narrows dorsally, contacting only a small part of postorbital (0) or extends dorsally as a broad sheet contacting most of the postorbital portion of postorbital bar (1).

20. Frontals narrow between orbits (similar in breadth to nasals) (0) or are broad, about twice nasal breadth (1).

21. Frontals paired (0) or fused (1).

22. Dorsal surface of frontal and parietal flat $(0)$ or with narrow midline ridge (1).

23. Frontal extends well into supratemporal fossa (0), or extends slightly or not at all (1).

24. Supratemporal roof with complex dorsal surface (0) or dorsally flat "skull table" developed, with flat shelves extending laterally beyond quadrate contacts (1).

25. Postorbital bar weak, lateral surface sculptured (if skull sculptured) (0) or postorbital bar robust, unsculptured (1) 
26. Postorbital bar transversely flattened, unsupported by ectopterygoid (0) or postorbital bar columnar, supported by ectopterygoid (1).

27. Vascular opening on lateral edge of dorsal part of postorbital bar absent (0) or present (1).

28. Postorbital bar without anterolateral process $(0)$ or with anterolateral process (1).

29. Dorsal part of postorbital with anterior and lateral edges only (0) or with anterolaterally facing edge (1).

30. Dorsal end of postorbital bar broadens dorsally, continuous with dorsal part of postorbital (0) or dorsal part of postorbital bar constricted, distinct from dorsal part of postorbital (1).

31. Bar between orbit and supratemporal fossa broad and solid, with broadly sculptured dorsal surface (0) or bar narrow, with sculpturing on anterior part only (1).

32. Parietal without broad occipital portion (0) or with broad occipital portion (1).

33. Parietal with broad, sculptured region separating supratemporal fossae (0) or with sagittal crest between fossae (1).

34. Postparietal (dermosupraoccipital) a distinct element (0) or not distinct (fused with parietal?) (1).

35. Posterodorsal corner of squamosal squared off, lacking extra "lobe" (0), or with unsculptured "lobe" (1).

36. Posterior edge of squamosal nearly flat $(0)$ or posterolateral edge of squamosal extending posteriorly as a long process (1).

37. Palatines do not meet on palate below narial passage (0), or form palatal shelves that do not meet (1), or meet ventral to narial passage, forming part of secondary palate (2).

38. Pterygoid restricted to palate and suspensorium, joints with quadrate and basisphenoid overlapping (0) or quadrate ramus of pterygoid extends dorsally to contact laterosphenoid and form ventrolateral edge of trigeminal foramen, strongly sutured to quadrate and laterosphenoid (1).

39. Choana opens ventrally from palate $(0)$ or opens posteriorly into midline depression (1).

40. Palatal surface of pterygoid smooth (0) or sculptured (1).

41. Pterygoids separate posterior to choana (0) or are fused (1).

42. Choana of moderate size, less than one-fourth of skull breadth (0), or choana extremely large, nearly half of skull breadth (1), or choana (secondary choana) very narrow and elongate, more than three times longer than wide (2).

43. Pterygoids do not enclose choana (0) or enclose choana (1).

44. Choana situated near anterior edge of pterygoid (or anteriorly) (0) or in middle of pterygoid (1).

45. Quadrate without fenestrae (0), or with single fenestra (1), or with three or more fenestrae on dorsal and posteromedial surfaces (2).

46. Posterior edge of quadrate broad medial to tympanum, gently concave $(0)$ or posterior edge narrow dorsal to otoccipital contact, strongly concave (1).

47. Dorsal, primary head of quadrate articulates with squamosal, otoccipital, and prootic (0) or with prootic and laterosphenoid (1).

48. Ventrolateral contact of otoccipital with quadrate very narrow $(0)$ or broad (1).

49. Quadrate, squamosal, and otoccipital do not meet to enclose cranioquadrate passage $(0)$, enclose cranioquadrate passage near lateral edge of skull (1), or meet broadly lateral to passage (2).

50. Pterygoid ramus of quadrate with flat ventral edge (0) or with deep groove along ventral edge (1).

51 . Ventromedial part of quadrate does not contact otoccipital (0), or contacts otoccipital to enclose carotid artery and form passage for cranial nerves IX-XI (1).

52. Eustachian tubes not enclosed between basioccipital and basisphenoid (0) or entirely enclosed (1).

53. Basisphenoid rostrum (cultriform process) slender (0) or dorsoventrally expanded (1).

54. Basipterygoid process prominent, forming movable joint with pterygoid (0) basipterygoid process small or absent, with basipterygoid closed suturally (1).

55. Basisphenoid similar in length to basioccipital, with flat or concave ventral surface (0) or basisphenoid shorter than basioccipital (1).

56. Basioccipital exposed on ventral surface of braincase (0) or virtually excluded from ventral surface by pterygoid and basioccipital (1).

57. Basioccipital without well-developed bilateral tuberosities (0) or with large, pendulous tubera (1)
58. Otoccipital without laterally concave descending flange ventral to subcapsular process $(0)$ or with flange (1).

59. Cranial nerves IX-XI pass through common large foramen vagi in otoccipital (0) or cranial nerve IX passes medial to nerves $\mathrm{X}$ and XI in separate passage (1).

60. Otoccipital without large ventrolateral part ventral to paroccipital process $(0)$ or with large ventrolateral part (1).

61. Crista interfenestralis between fenestrae psuedorotunda and ovalis nearly vertical (0) or horizontal (1).

62. Supraoccipital forms dorsal edge of foramen magnum (0) or otoccipitals broadly meet dorsal to foramen magnum, separating supraoccipital from foramen (2).

63. Mastoid antrum does not extend into supraoccipital (0) or extends through transverse canal in supraoccipital to connect middle ear regions (1)

64. Posterior surface of supraoccipital nearly flat (0) or with bilateral posterior prominence (1)

65. One small palpebral present in orbit (0), or two large palpebrals present (1), or one large palpebral present (2).

66. External naris divided (0) or confluent (1)

67. Antorbital fenestra as large as orbit (0), or about half the diameter of orbit (1), or much smaller than orbit (2), or absent (3).

68. Supratemporal fenestrae much longer than orbits (0) or equal in length or much shorter than orbits (1).

69. Choana confluent (0) or divided by septum (1).

70. Dentary extends posteriorly under mandibular fenestra (0) or does not extend beneath fenestra (1)

71. Retroarticular process very short and robust (0), or absent (1), or short, robust and ventrally situated (2), or posterodorsally curving and elongate (3), or posteroventrally projecting and paddle-shaped (4), or posteriorly projecting from ventral part of mandible and attenuating (5).

72. Prearticular present (0) or absent (1).

73. Articular without medial process articulating with otoccipital and basisphenoid (0) or with process (1).

74. Dorsal edge of surangular flat (0) or arched dorsally (1).

75. Mandibular fenestra present (0) or absent (1).

76. Insertion area for $M$. pterygoideus posterior does not extend onto lateral surface of angular (0) or extends onto lateral surface of angular (1).

77. Splenial not involved with symphysis $(0)$, or involved slightly in symphysis (1), or involved extensively in symphysis (2).

78. Posterior two premaxillary teeth similar in size to anterior teeth (0) or much longer (1).

79. Maxillary teeth homodont, with lateral edge of maxilla straight (0), or teeth enlarged in middle of tooth row, with edge of maxilla extending outward at these loci (1), or teeth enlarged and edge of maxilla curved in two waves ("festooned") (2).

80. Anterior dentary teeth opposite premaxilla-maxilla contact no more than twice the length of other dentary teeth $(0)$ or more than twice the length (1).

81. Dentary teeth posterior to tooth opposite premaxilla-maxilla contact homodont (0) or enlarged opposite smaller teeth in maxillary tooth row (1).

82. Anterior and posterior scapular edges symmetrical in lateral view (0) or anterior edge more strongly concave than posterior edge (1).

83. Coracoid no more than half the length of scapula (0) or about equal in length to the scapula (1).

84. Anterior process of ilium similar in length to posterior process $(0)$ or one-quarter or less the length of the posterior process (1).

85. Pubis rod-like, without expanded distal end (0) or with expanded distal end (1).

86. Pubis forms anterior half of ventral edge of acetabulum (0) or pubis at least partially excluded from acetabulum by anterior process of ischium (1).

87. Distal end of femur with large lateral facet for fibula (0) or with very small facet (1).

88. Fifth pedal digit either with (0) or without (1) phalanges.

89. Atlas intercentrum broader than long (0) or as long as broad (1).

90. Neural spine on posterior cervical vertebrae as broad as those on anterior cervical vertebrae $(0)$ or anteroposteriorly narrow, rod-like (1).

91. Cervical vertebrae without well-developed hypapophyses (0) or with well-developed hypapophyses (1). 
92. Cervical vertebrae amphicoelous or amphiplatyan (0) or procoelous (1).

93. Trunk vertebrae amphicoelous or amphiplatyan (0) or procoelous (1).

94. All caudal vertebrae amphicoelous or amphiplatyan (0), or first caudal vertebra biconvex, with other caudal vertebrae procoelous (1), or all caudal vertebrae procoelous (2).

95. Dorsal osteoderms rounded, ovate $(0)$, or rectangular, broader than long (1), or square (2).

96. Dorsal osteoderms with straight anterior edge (0) or with anterolateral process laterally on anterior edge (1).

97. Dorsal osteoderms arranged in two parallel, longitudinal rows (0) or in more than two longitudinal rows (1).

98. Some or all osteoderms imbricated (0) or osteoderms sutured to one another (1).

99. Tail with dorsal osteoderms only ( 0 ) or completely surrounded by osteoderms (1).

100. Osteoderms absent from ventral part of trunk (0) or present (1).

101. Osteoderms with longitudinal keels on dorsal surfaces $(0)$ or without keels (1).

102. Surangular forms only lateral wall of glenoid fossa (0) or surangular forms approximately one-third of the glenoid fossa (1).

103. Anterior margin of femur linear (0) oranterior margin of femur bears flange for coccygeofemoralis musculature (1).

104. Teeth without carinae, or with smooth carinae (0) or teeth serrated (1).

105. Dentary smooth lateral to seventh alveolus (0) or dentary with large occlusal pit lateral to seventh alveolus (1).
106. Scapular blade no more than twice the length of the scapulocoracoid articulation ( 0 ) or scapular blade very broad and greater than twice the length of the scapulocoracoid articulation (1).

107. Dorsal edge of dentary straight (0) or dorsal edge of dentary sinusoidal, with two concave waves (1).

108. Compressed dentary (0) or transversely expanded dentary, almost as wide as high (1).

109. Lateral surface of dentary continuous, without longitudinal groove $(0)$ or lateral surface of dentary with longitudinal groove (1).

110. Splenial thin posterior to symphysis (0) or splenial robust posterodorsal to symphysis (1).

111. Prefrontals broad (0), or narrow and short (1), or narrow and long (1).

112. Snout long (0), or relatively broad and shorter than the remainder of the skull (1), or narrow and shorter than the remainder of the skull (1).

113. Posterior cheek teeth not multicusped (0), multicusped with cusps in single row (1), or multicusped with cusps in more than one row (2).

114. Occipital condyle in posterior position (0) or posteroventral position (1).

115. Vomer exposed (0) or not exposed (1) on palate.

116. Posterior cheek teeth conical (0), or laterally compressed (1), or strongly spatulate (2).

117. Cheek teeth not constricted at base of crown (0) or constricted (1)

118. Maxillary depression absent (0) or present (1) on lateral surface of maxilla.

119. Long anterior processes of pterygoids that contact the maxillae anteromedial to primary choanae absent (0) or present (1).

APPENDIX 2

\begin{tabular}{|c|c|c|c|c|c|c|}
\hline & $\begin{array}{l}1 \\
0\end{array}$ & $\begin{array}{l}2 \\
0\end{array}$ & $\begin{array}{l}3 \\
0\end{array}$ & $\begin{array}{l}4 \\
0\end{array}$ & $\begin{array}{l}5 \\
0\end{array}$ & $\begin{array}{l}6 \\
0\end{array}$ \\
\hline Notosuchus & ?12?001101 & 0100111010 & $11 ? 110 ? 011$ & $0000002 ? ? 0$ & $? 000201120$ & $11 ? 1000 ? 10$ \\
\hline Baurusuchus & 0000001111 & ??00? 11010 & 1??110?011 & 0?????2? 10 & 11 ?? 111120 & $11 ? 1000 ? ? 0$ \\
\hline Libycosuchus & ?10?001101 & ??00? 11010 & $10 ? 110 ? 011$ & $000 ? 002 ? ? ?$ & ??00? 11120 & $11 ? 1010 ? ? 0$ \\
\hline Sebecus & $1000 ? 01101$ & $0000 ? 11000$ & $11 ? 111 ? 0 ? 1$ & 0001012110 & $1100 ? 11120$ & $1111000 ? ? 0$ \\
\hline Araripesuchus & 1121011121 & 0100211010 & 1011110011 & $0001 ? 02110$ & $100011112 ?$ & $11 ? 1000 ? ? 0$ \\
\hline Alligatorium & $112101 ? 03 ?$ & $0000 ? 10000$ & $101111 ? 00 ?$ & $100 ? 10 ? ? ? 0$ & ??00??11?? & 1??1000??? \\
\hline Theriosuchus & $112101 ? 131$ & 0100110000 & 1101111001 & 1001102110 & $10001 ? 11 ? 0$ & $1111000 ? ? ?$ \\
\hline Pelagosaurus & $111 ? 011101$ & 0011020101 & 0000000000 & 0001012110 & 1000000110 & 1111001001 \\
\hline Teleosauridae & $011 ? 011101$ & 0011010100 & 1000000000 & 0011002110 & $1000 ? 00110$ & 1111001011 \\
\hline Metriorhynchidae & $011 ? 011101$ & $0011 ? 20101$ & 1000000000 & 0011002110 & $? 000 ? 00110$ & 1111001011 \\
\hline Eutretauranosuchus & 112 ?? 1? 1? 1 & 0010211000 & $100111 ? 00 ?$ & 0001001110 & ?200? 11120 & $11 ? 1010 ? ? 0$ \\
\hline Goniopholis & $112 ? 01 ? 131$ & ?010? 11000 & $100111 ? 001$ & $0001002 ? 10$ & $1000 ? 11120$ & $11 ? 1010 ? 10$ \\
\hline Bernissartia & 112 ? 111131 & ??00? 11000 & $10 ? 111 ? 001$ & $000 ? 002 ? ? ?$ & ??0001112? & $11 ? 10100 ? 0$ \\
\hline Crocodylia & 1120111131 & 0000211000 & 1001111001 & 0001002110 & 1011011120 & 1111010010 \\
\hline Protosuchus & 0000000010 & $0000 ? 00010$ & 0011000001 & $0011 ? 00101$ & 0000201101 & 1111100101 \\
\hline Hemiprotosuchus & ?00??0?1?? & ????? 10010 & ?0??00?001 & 0011 ????01 & ??0020?00? & $11 ? 1100101$ \\
\hline Orthosuchus & $100 ? 000110$ & $1 ? 00010010$ & 0011000001 & $0001000 ? 00$ & 0000001100 & $1111100 ? ? 1$ \\
\hline Mahajangasuchus & 1????????? & ????? ?? ??? & ?? ?? ?? ? ?? & ???? ?? ??? ? & ??? ????? ?? & ?? ?? ? ? ? ? ? \\
\hline Peirosauridae & $112 ? 111121$ & $1 ? 002 ? 10 ? 0$ & $100111 ? 011$ & 0001012110 & $11001 ? 112 ?$ & $1111000 ? 00$ \\
\hline Hsisosuchus & 100 ?????? 1 & $1 ? 00 ? 00010$ & $10011 ? 0011$ & 0001012110 & $1000101 ? 11$ & $11 ? 1000 ? 0 ?$ \\
\hline Trematochampsa & $112 ? 0011 ? 1$ & $00 ? ? 211 ? ? 0$ & $100111 ? 011$ & $000101 ? ? ? ?$ & ????11112? & 11 ???? 0000 \\
\hline Uruguaysuchus & $011 ? 0 ? ? 10 ?$ & ??00??1?? 1 & 1??????? 1 ? & 1?? 1? 12?1? & ?00011???? & ?? ??? ?? ??? \\
\hline Malawisuchus & $010 ? 00 ? 101$ & $0100 ? 11110$ & $11111 ? 011 ?$ & $0001012 ? ? 0$ & $100020 ? 11 ?$ & ???? ?00??? \\
\hline Comahuesuchus & $00 ? ? 0 ? ? 101$ & 1 ?00?????0 & ?11??????? & ?001002??? & ????1??1?? & ?????????? \\
\hline Simosuchus & 1120101100 & $1 ? 00 ? 00010$ & $110110 ? 011$ & $0001011 ? 10$ & $110001 ? 110$ & 01 ???00011 \\
\hline Sunosuchus & $112 ? 010131$ & $1 \mathrm{~N} 10 ? 11000$ & 1001111001 & 0001002210 & 1200111120 & $11110100 ? 0$ \\
\hline Calsoyasuchus & $112 ? 010131$ & $0210 ? 1 ? ? ? 0$ & $10111 ? 1001$ & 0?????1?1? & ?200?????? & ?? ?? ? ? ??? \\
\hline
\end{tabular}


APPENDIX 2, continued

\begin{tabular}{|c|c|c|c|c|c|c|}
\hline & $\begin{array}{l}7 \\
0\end{array}$ & $\begin{array}{l}8 \\
0\end{array}$ & $\begin{array}{l}9 \\
0\end{array}$ & $\begin{array}{r}10 \\
0\end{array}$ & $\begin{array}{r}11 \\
0\end{array}$ & $\begin{array}{r}11 \\
9\end{array}$ \\
\hline Notosuchus & ?110??11?? & 5?010?110? & 0 ?? 1 ??? ?? 0 & 0?0??????? & ?0??0?0000 & $0101 ? 1000$ \\
\hline Baurusuchus & ?11??03?01 & $5 ? 01011101$ & 0????????? & 0?????? ??? & ?0?1??0011 & 01 ?? ? 1000 \\
\hline Libycosuchus & ???0?0? 1?? & $5 ? 0001 ? 000$ & 0???????? 0 & 0?0??????? & ?? ?1??00?? & ?10???? 00 \\
\hline Sebecus & ?1?? 103100 & 5100011000 & 0????????0 & ?00??????? & ?0010?001? & 010011000 \\
\hline Araripesuchus & ?11?101100 & $5 ? 00011010$ & $11111111 ? 0$ & $10002 ? 0 ? ? ?$ & ? 010011100 & 000101000 \\
\hline Alligatorium & ????10?1?? & $4 ? 00101 ? 10$ & 1101111100 & ?? ?? 1 ? 0010 & 0000001100 & 010 ????0? \\
\hline Theriosuchus & ??1?10210? & $4 ? 00101010$ & $1101111 ? ? 0$ & $011 ? 110010$ & 0000001100 & 000010000 \\
\hline Pelagosaurus & ? $10001200 ?$ & 3000012000 & $0110111 ? 00$ & 0000110001 & 1000000100 & 000010000 \\
\hline Teleosauridae & ?1?001200? & $3 ? 00012000$ & $00101111 ? 0$ & $000 ? 110001$ & 0000000100 & $0000 ? 0000$ \\
\hline Metriorhynchidae & ?1?001200? & 3000112000 & $00101 ? 11 ? 0$ & 000 ???? ?? 0 & $? 000000100$ & $? 00010000$ \\
\hline Eutretauranosuchus & ? $1 ? 0 ? 12110$ & $4 ? 00001010$ & 111 ??? 1 ?? 0 & ??0?11???? & 1000001100 & 000010011 \\
\hline Goniopholis & ?1?011311? & $4 ? 001 ? 1010$ & 11 ?1??1??0 & ?00?1100? 1 & 1000001100 & 000010010 \\
\hline Bernissartia & ?1???131?? & $4 ? 0010 ? 010$ & $11 ? 1 ? 11 ? ? 0$ & 0002101011 & 0000001100 & 000010000 \\
\hline Crocodylia & 1110013100 & 3100011010 & 1111111101 & 1111101011 & 1000001100 & 000010000 \\
\hline Protosuchus & $01101011 ? 1$ & 2011001101 & 0100011100 & $000 ? 110011$ & $000000000 ?$ & $0200 ? 0000$ \\
\hline Hemiprotosuchus & ??1?1?11?? & 2?11???? 01 & ?? ??? ?? ? ? 0 & ???? 1 ? 00 ? 1 & $? 00000000 ?$ & $0200 ? 0 ? 00$ \\
\hline Orthosuchus & ?1?01011?0 & $? 000 ? 00100$ & 0100011100 & $000 ? 110010$ & $000000000 ?$ & 200000000 \\
\hline Mahajangasuchus & ?? ??? ? ? ? 1 & $51010 ? ? ? ? 0$ & $11 ? 1111 ? 01$ & $10000010 ? ?$ & ? 111111001 & ??0??000? \\
\hline Peirosauridae & ?1?0??2000 & ????0?1?1? & ???? ?? ? ?? & ???? ?? ???? & ??????11? 1 & ?? ?? ? 1000 \\
\hline Hsisosuchus & ?1?02? 1001 & $1 ? 000 ? 1 ? 10$ & 010 ?01???? & ???? 1?0011 & $00 ? 00000 ? ?$ & $2000 ? 0000$ \\
\hline Trematochampsa & ?1?0??10?? & 5? 0???1??? & ?? ???????? & $100020 ? 0 ? ?$ & ?1111?1100 & ??? 0 ? 0000 \\
\hline Uruguaysuchus & ?????? 111 ? & ????0??000 & 1??1?1???? & ?????????? & ??11??0??? & ?011?2100 \\
\hline Malawisuchus & ?? ? ? 1 ? 2100 & $41 ? 00 ? 111 ?$ & 1???? ?? ??? & 100 ? ??? ??? & 1??0??0??? & $1121 ? 1100$ \\
\hline Comahuesuchus & 1???? 1 ? 1 ? 0 & ????0? 1010 & 0????????? & ??????? ??? & ???00??00? & ?10??0?00 \\
\hline Simosuchus & ?1?0102111 & $41010 ? 0000$ & 0??????? 01 & $000 ? 2010 ? 1$ & $00 ? 20 ? 0000$ & 111102100 \\
\hline Sunosuchus & ?21021311? & 4100011010 & 1??1111?0? & $00001100 ? 1$ & 1????????? & ?00?1??10 \\
\hline Calsoyasuchus & ?? ??? 1111 ? & ????? ??01? & ?? ??? ?? ??? & ?? ?? ??? ??? & ?? ?1??? ??? & 00??1?? 11 \\
\hline
\end{tabular}

